\title{
Absolutely Positively Ageing: Positive ageing and volunteering in Wellington, Aotearoa New Zealand
}

Alice Christina Clowes

2016

School of Geography, Environment, and Earth Sciences

A thesis submitted to Victoria University of Wellington in partial fulfilment of the requirements for the degree of Master of Development Studies 


\section{Abstract}

Population ageing is a key development issue worldwide, and governments around the world are working to address the changing needs that accompany this demographic shift (Vos, Ocampo \& Cortez, 2008). In New Zealand, the Government and the Wellington City Council have developed the Positive Ageing Strategy (2001) and the Positive Ageing Policy (2012) respectively in response to population ageing. Both the Strategy and the Policy pay particular attention to the importance of the continued social inclusion of older people in their communities. One of the ways that this inclusion is encouraged is through older people's participation in voluntary activities.

This research explores the lived experiences of older people who volunteer in the Wellington region to understand the nature of the relationship between volunteering and positive ageing. The exploratory nature of the research necessitated a qualitative research design. Through semi-structured interviews with 12 members of the volunteer community I explored the underlying themes of this research project including motivations for participation in voluntary work, skills and knowledge brought to and developed through volunteering, challenges and barriers to participation in voluntary work, and the participants' awareness of representations and stereotypes around ageing.

The research findings illustrate the complexities inherent in the relationship between volunteering and positive ageing and show how volunteering was used by the participants as a means to resist and challenge negative stereotypes and representations of ageing. There was a fine balance between the promotion of volunteering as one of a multitude of ways in which older people can participate in their communities and overstating the benefits of volunteering to individuals and their communities without revealing the potential challenges. 


\section{Acknowledgements}

I would first and foremost like to thank the participants who so generously gave up their time to share their stories of ageing and volunteering with me. Your dedication to the community is inspiring.

To my supervisor, Polly Stupples: thank you for your patience, encouragement and constructive feedback - your "(-)" comments kept me going when the going got tough. John Overton, thank you for your kind support and guidance in the early stages of developing this work.

Many many thanks to my friends and family who kindly proofread parts of this work: Liam Clowes, Fiona Millar, Elizaveta Sopina, Anna Wright, Ryan Hammond, and Rebecca Hofmann. I'm so fortunate to have you in my life.

To DEVE-ous and my development studies classmates: I was scared when I started this degree in 2014 that I wouldn't make any friends, and the next two years would be a sad, lonely existence. How lucky that I was wrong! Hope to see you again at Red Hill (or the Cambodian/Lao/Vietnamese equivalent) soon.

To my partner John and my flatmates: thank you for listening to my whinging and panicking, and for your leniency with the chores roster when I had so many deadlines to meet.

To my mum, Jane, and my family and friends: thank you for the care packages, the pep talks, and your acceptance of my long silences. Knowing that I had your support meant so much.

Finally, to my late grandparents Margaret and Allan Renwick: neither of you are here to see this work, but without your influence on our family this thesis would not have come to be. Thank you for being such a strong guiding force in my life and showing me the importance of valuing and caring for other people, and the world we live in. 


\section{Table of Contents}

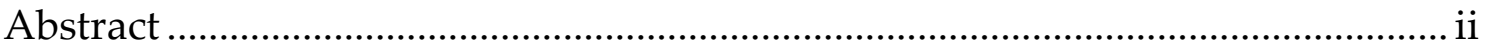

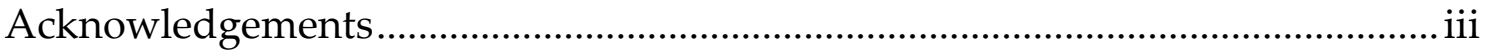

List of Figures and Tables.................................................................................... vii

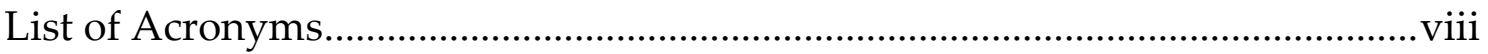

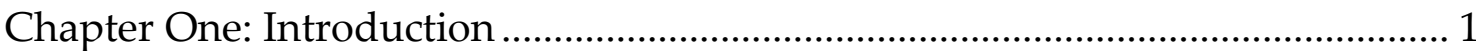

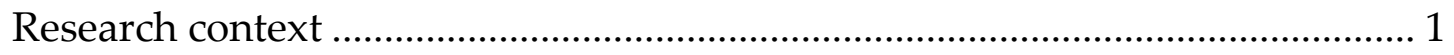

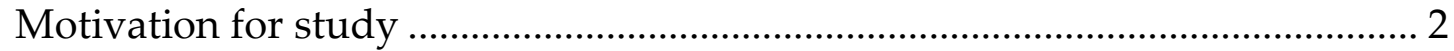

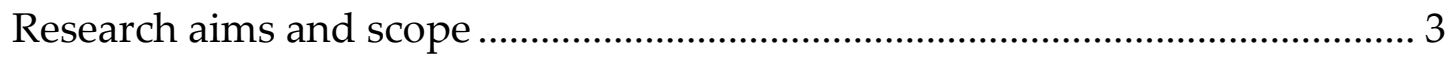

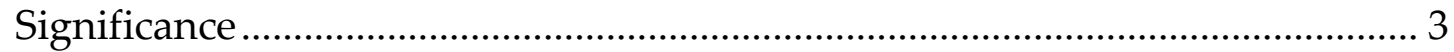

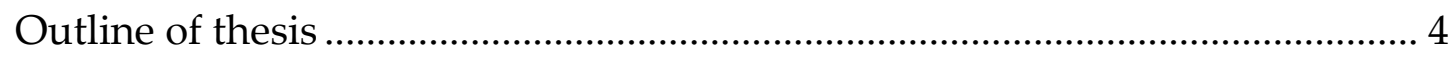

Chapter Two: Literature Review ......................................................................... 5

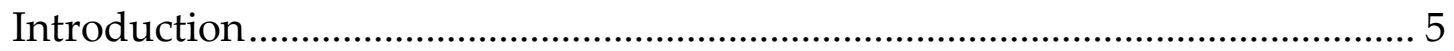

Development and Population Ageing ............................................................ 6

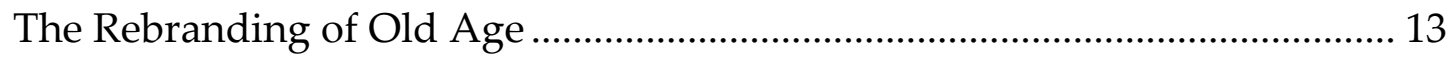

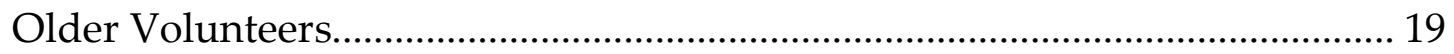

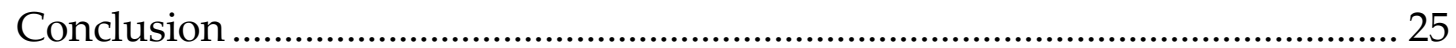

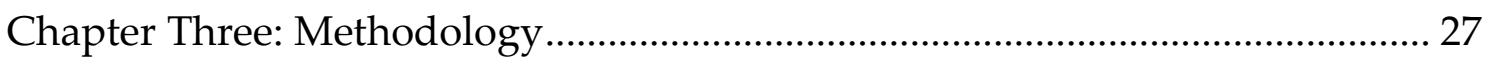

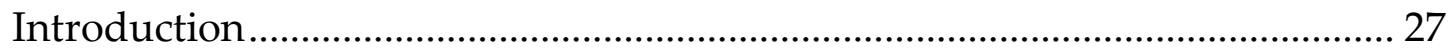

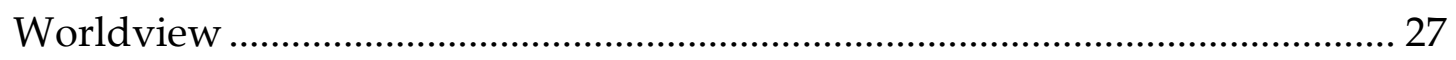

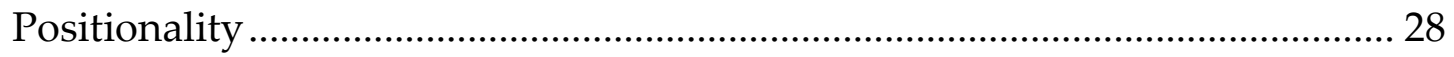

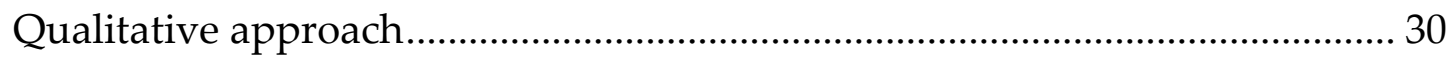

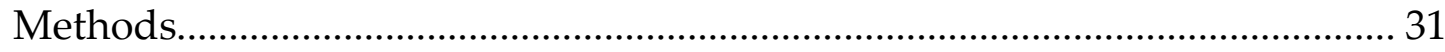

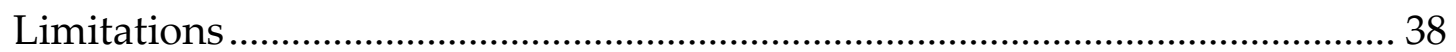


Conclusion

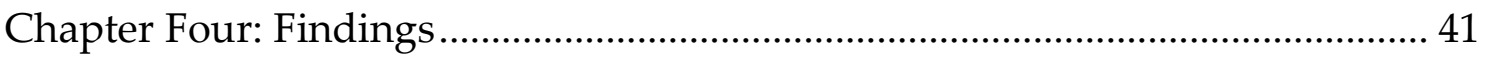

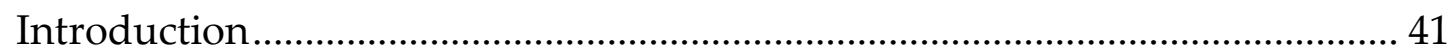

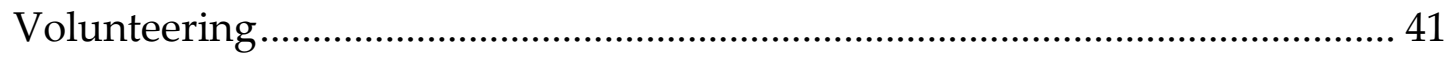

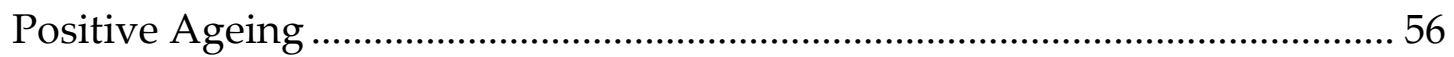

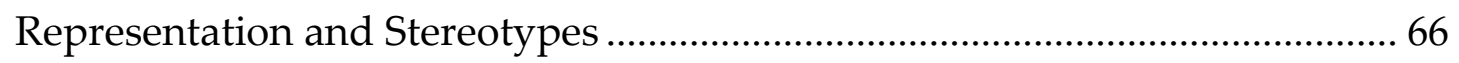

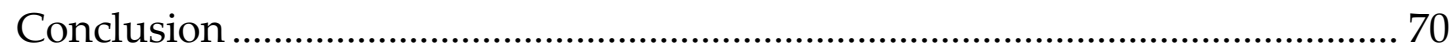

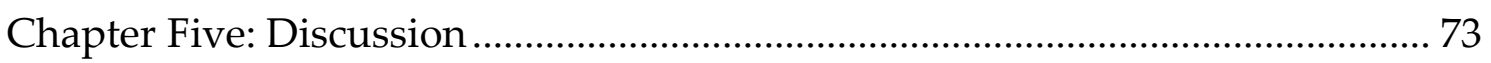

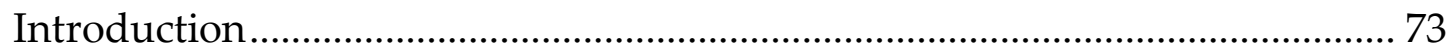

RQ1: What is motivating older people in Wellington to volunteer in their

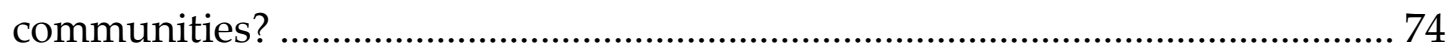

RQ2: What skills and knowledge are older volunteers bringing to and gaining through their voluntary work? ......................................................................... 75

RQ3: What challenges and barriers to participation in volunteering do the older volunteers identify, and what solutions do they put forward to address these? 77

RQ4: To what extent do stereotypes around ageing impact on the experiences of the older volunteers?

What is the nature of the relationship between volunteering and positive ageing?.

Conclusion 86

Chapter Six: Conclusions. 87

Overview of thesis 87

Key conclusions 88

Recommendations for practice 91 


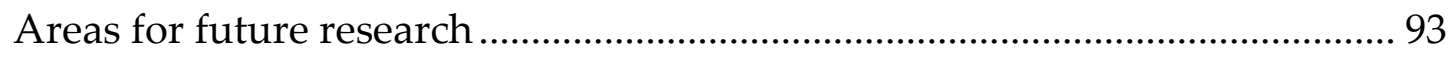

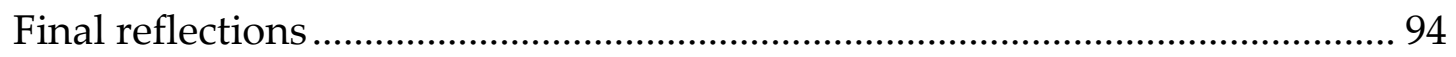

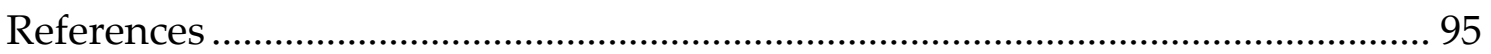

Appendix One: Victoria University of Wellington Ethics Forms ....................... 102

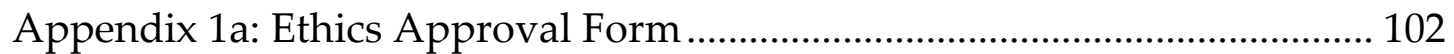

Appendix 1b: Participant Information Sheet................................................ 103

Appendix 1c: Participant Consent Form ......................................................... 104

Appendix Two: Semi-structured interview protocol ......................................... 105 


\section{List of Figures and Tables}

Figure 1: The 10 Positive Ageing Goals..................................... 20

Figure 2: Participants' definitions of positive ageing ........................ 57

Table 1: Voluntary roles of the research participants........................ 32 


\section{List of Acronyms}

HDI Human Development Index

IMF International Monetary Fund

OECD Organization for Economic Co-operation and Development

PAP Positive Ageing Policy

PAS Positive Ageing Strategy

SAP Structural Adjustment Programme

SDG Sustainable Development Goals

UN United Nations

UNFPA United Nations Population Fund

UNV UN Volunteers

WHO World Health Organization 


\section{Chapter One: Introduction}

\section{Research context}

Population ageing is affecting countries in all regions of the world. Both developing and developed nations are experiencing this demographic shift, and the phenomenon has been highlighted as a prominent theme for development going forward (Vos, Ocampo \& Cortez, 2008). For Aotearoa New Zealand, projections based on the 2013 census indicate that the number of people aged 65 and over will have doubled by 2038 (Statistics New Zealand, 2015). Population shifts such as these have global significance.

This demographic shift brings concerns around welfare, labour markets, healthcare costs and social inclusion to the forefront of social policy debates concerning the growing social group of older people. Combined with these concerns, negative attitudes and discourses around older people tend to frame them as frail, unproductive drains on society's limited resources with little to contribute (Kam, 1996; Onyx \& Benton, 1995; Vos et al., 2008). Such attitudes can contribute to a culture wherein elder abuse or neglect prevails and older people are excluded from participation in mainstream society (Vos et al., 2008).

Positive ageing (also known as active ageing, and stemming from concepts of productive ageing, and successful ageing) is a policy approach promoted by organisations such as the World Health Organisation (WHO) (2002) and the Organisation for Economic Co-operation and Development (OECD) (2011) as a means of positively reframing ageing to both counter the negative discourses and attitudes and address the supposed challenges of ageing populations. The New Zealand Government and the Wellington City Council have both adopted positive ageing approaches in developing policy around population ageing.

The New Zealand Government has adopted 10 Positive Ageing Goals as part of its Positive Ageing Strategy (PAS), and the Wellington City Council has also 
adopted these goals (with the exception of those relating to rural New Zealand) in formulating its Positive Ageing Policy (PAP). The PAS and PAP will be discussed further in Chapter Two of this thesis, but it is important here to note the shared assumption of the PAS and PAP that volunteering is an aspect of a positive ageing experience. This assumption suggests that volunteering benefits individuals, communities and society at large, as volunteering tends to be presented in uncomplicated terms as a positive activity for older people to engage in. This idea will be further explored throughout this thesis.

\section{Motivation for study}

The lack of qualitative information regarding the motivations and experiences of volunteers has motivated the current study. The concept of positive ageing can help challenge negative discourses of ageing and build a more nuanced view of the phenomenon of population ageing in order to recognise the many contributions that older people make to society and community well-being (Onyx \& Benton, 1995; Hardhill \& Baines, 2009; Wiles \& Jayasinha, 2013; Rawsthorne, 2012). However, positive ageing has also faced criticisms due to its connections with neoliberal ideologies placing emphasis on individual responsibility at the same time as support from governments is diminishing. A common method through which older people contribute is unpaid voluntary work, as recognised by the PAS and PAP. Currently the way that the New Zealand Government measures the progress of the positive ageing goal relating to volunteering is through a quantitative approach which measures the numbers of older people engaged in voluntary work. Although this measure is clearly useful in part, a purely quantitative approach does not recognise the motivations and experiences of volunteers which may provide a more nuanced view of volunteering and positive ageing. 


\section{Research aims and scope}

In response to the above motivation for this research I have developed the following research questions which guide this research project:

Primary question: What is the nature of the relationship between volunteering and positive ageing?

Sub-questions:

1 - What is motivating older people to volunteer in their communities?

2 - What skills and knowledge are older volunteers bringing to and gaining through their voluntary work?

3 - What challenges and barriers to participation in volunteering do the older volunteers identify, and what solutions do they put forward to address these?

4 - To what extent do stereotypes around ageing impact on the experiences of the older volunteers?

The scope of this research is limited to a small group of twelve older volunteers based in Wellington due to limitations in time and budget.

\section{Significance}

This thesis contributes to a growing body of research centred on honouring the contributions that older people make to their communities through voluntary work (for example Wiles \& Jayasinha, 2013). By utilising a qualitative approach to the exploration of lived experiences of a group of older volunteers in Wellington, this thesis will add a rich layer of data to otherwise quantitative information collected by the New Zealand Government and Wellington City Council in monitoring the progress of the PAS and PAP in relation to volunteering. This research project will contribute to a nuanced view of 
volunteering and positive ageing which has room for negative as well as positive understandings of the two. This contribution is important in challenging overly positive or overly negative discourses around ageing and older people (Wiles \& Jayasinha, 2013).

The findings of this research project relating to challenges and barriers to participation in voluntary work, as well as solutions put forward by the research participants in addressing the challenges/barriers will be of use to the New Zealand Government and Wellington City Council, voluntary organisations, and current and potential volunteers.

\section{Outline of thesis}

Following this Introduction, Chapter Two consists of a literature review which serves to further contextualise this project within the field of development studies, reviewing literature relating to central concepts of population ageing, positive ageing and older volunteers in order to build a conceptual framework for the research. In Chapter Three I expand on my positionality and epistemological standpoint, and set out the research design, justifying the qualitative research approach and explaining the methods for data collection and analysis. In Chapter Four the research findings gathered from interviews with 12 older volunteers are set out thematically in relation to the guiding research questions. They range from practical findings relating to experiences, challenges and barriers to less tangible findings relating to stereotypes and identity. Chapter Five contains a discussion of the research findings and positions them in relation to the wider literature and theory. Chapter Six concludes the thesis and makes recommendations for future practice and future research. 


\section{Chapter Two: Literature Review}

\section{Introduction}

This thesis aims to explore the nature of the relationship between volunteering and positive ageing with reference to the lived experiences of older volunteers in Wellington. This entails an exploration not only of the experiences of volunteers but the positioning of this research within the New Zealand Government and Wellington City Council policies on ageing. There are a number of factors influencing these experiences, including demographic change, neoliberal economic policy, and societal expectations and views of older people. In this literature review I will put forward the conceptual framework that shapes my research approach and informs my approach to analysis in this thesis.

I begin by reviewing global literature on population ageing and development to firmly situate my research within contemporary development debates around this issue, which is occurring in all regions of the world and is currently being addressed by policymakers in Aotearoa New Zealand. I review postdevelopment literature which has shaped my understandings of development, before moving on to a balanced review of academic literature on population ageing, and the policy context that has shaped policy discussions and priorities which will be discussed later in the review.

In the next section I review literature relating to the 'rebranding of old age'. The purpose of this section is to illustrate changing paradigms around ageing and link them back to the Aotearoa New Zealand context and in particular the context of my research. The section explores the background and development of positive and active ageing approaches to the issue of population ageing.

Finally I position older volunteers within the above context. In the third section of this literature review I explore the literature relating to older volunteers, which has grown in significance within the changing policy landscape. Using the 
concepts of reciprocity, care and empowerment, I will examine the positioning of older volunteers in relation to policies of active or positive ageing. Throughout there will be a focus on motivations for volunteering and the differing standpoints of government/council and individuals. This section refers back to both the population ageing and rebranding of ageing sections to integrate the key conceptual debates.

The approach I have taken to this literature review is illustrative of my postdevelopment social constructivist standpoint which is further detailed in my methodology in Chapter Three. Therefore, within this review, I have paid particular attention to the discursive framing of development, population ageing, and volunteering, and the varying competing constructions of meaning within the texts surveyed. Although it is not within the scope of this thesis to undertake a full discourse analysis, I do pay heed to Cornwall's (2007) statement that "words make worlds" (p. 471) and my analysis of the literature reflects that belief. Language has powerful constructive and deconstructive functions which are important to be aware of when undertaking research that attempts to explore the social worlds of the ageing (Hazan, 1994). Discourses and stereotypes need to be explored within the literature I am surveying because of the inherent power they have to affect policy and real world decision making. They reveal ambivalences about older people and ageing on global, national and community levels that help make sense of the current state of responses to population ageing and the positions of older volunteers within the current setting.

\section{Development and Population Ageing}

In this section I explore post-development literature and the development literature relating to the topic of population ageing. The post-development texts provide a framework for my approach to this research project as a development studies thesis. The population ageing texts provide a framework for action on 
ageing for governments around the world and are therefore shaping decisions made by policymakers when deciding how to respond to population ageing. The purpose of this section is to first provide background information about population ageing, then highlight the dominant discourses within the literature and the problematic positioning of development as progress and age as decline.

\section{Post-development}

Broadly speaking, post-development is a critique of traditional development and earlier post-development theorists advocated for the total rejection of development and development practice (see Ziai, 2007). Post-development theory takes many forms and cannot be narrowed down to one school of thought (Ziai, 2007; Nustad, 2007). Standard critiques of post-development theory claim that post-development does not offer any "constructive alternatives" (Ziai, 2007, p. 115), but such critiques are misrepresenting the diversity of post-development thought. Keeping that in mind, there are aspects of post-development theory(ies) that have helped to shape this research project. It is acknowledged that the terms 'development', 'developed' and 'underdeveloped' are Eurocentric terms that position some states as superior and others inferior (Ziai, 2007, p. 8; Pieterse, 2001). In this thesis I use the terms 'developing' and 'developed' in quotation marks to indicate that I am uncomfortable with the binary thinking that seeks to separate the two, as if 'developed' countries have reached a finish line (Escobar, 2005).

It has been suggested that researchers in the West and those who are relatively privileged should not ignore situations in their 'own backyard' in favour of studying the far off poor (Jones, 2000; Matthews, 2008). Matthews (2008) argues that terms like 'First World' and 'Third World' group people together who may have significantly different living situations, and that "there are people living in what could be called Third World conditions in the First World and vice versa" (p. 1036). This attention to the nuances within countries further illustrates the 
problems with the binary thinking behind 'developed' and 'underdeveloped'/'developing'. The Aotearoa New Zealand context of this thesis is discussed below, and post-development thinking is instrumental in explaining why this research has been carried out in this context.

Productivity is a concept central to understandings of socioeconomic development, as is further discussed below. Gibson-Graham (2007) in their work on community economies argue for an expanded view of productivity. They seek to widen their "knowledge of economy through an exploration of the diverse ecologies of productivity" (p. 147). The term 'diverse economies' works to expand understandings of the mainstream economy and reveal previously hidden "economic "others"” (Gibson-Graham, 2007, p. 150), ways of sustaining livelihoods and wellbeing that are not normally considered or acknowledged as existing. A diverse economy is made up of not only market transactions, wage labour and capitalist enterprise, but also alternatives to each of these as well as non-market transactions, unpaid labour, and non-capitalist enterprise (GibsonGraham, 2007, p. 151). Volunteering falls into the unpaid labour section of the diverse economy and through seeking to understand more about volunteering I expand my understandings of productivity.

The Sustainable Development Goals (SDGs) are a set of 17 goals that make up the 2030 Agenda for Sustainable Development which has been adopted by the 193 Member States of the United Nations (UN) (UN, 2015a). The SDGs will guide Member States over the next 15 years in terms of their development agendas and policies. The global nature of the goals has been said to indicate a shift "towards development conceived as an ongoing issue in every society" (Howard \& Wheeler, 2015, p. 555), in contrast to past development agendas which have emphasised differences between the global 'North' and global 'South'. This shift supports the work of Jones (2000) discussed above. The 'universal' nature of the goals can be seen in the language used, for example with a recurring use of "for 
all" throughout most of the 17 goals (UN, 2015a). Long (2015) suggests that critics of economics-heavy conceptions of development may find the SDGs to present a "better vision of development than what has gone before" (p. 205) with the inclusion of concerns such as the environment, equality and participation.

Perhaps due to the universality of the goals there is no goal specifically related to older people or population ageing - "for all" can be taken to mean people at all ages and in all areas of the world. The goal that most closely references issues relevant to this thesis is SDG 3: "ensure healthy lives and promote well-being for all at all ages" (UN, 2015a). Some of these ideas of health and well-being will be explored below through a review of literature that directly references population ageing and development.

\section{Background to Population Ageing}

It is widely agreed that population ageing is occurring in all regions of the world, and that this demographic shift is irreversible (United Nations Population Fund (UNFPA) \& HelpAge International, 2012; WHO, 2012; UN, 2013; Vos, et al, 2009). In practical terms population ageing occurs because the number of births around the world is falling, whilst the number of people reaching 60 and above is increasing (WHO, 1999). Within this growing group of older people, ageing is also occurring. In the Aotearoa New Zealand context, population ageing among people aged 65 years and over has been documented with a projection that by the year 2063 the number of people aged 85 and over will make up 23.4 percent of that age group, nearly double the 2013 proportion (Statistics New Zealand, 2015).

Although population ageing is occurring in all regions of the world, it is not occurring at the same rate or to the same extent in all regions. 'Developed' countries have largely been experiencing this population shift over longer 
periods of time, granting them the opportunity to develop infrastructure to support this shift. In contrast, in many 'developing' countries, population ageing has been occurring at a rapid pace, with much less time for them to adapt or prepare (WHO, 2012; UN, 2002).

Aspects of population ageing that recurred throughout reports and recommendations from organisations such as the WHO and the UN included issues of health and labour. Health was emphasised in relation to the shift globally from infectious diseases to the growing dominance of noncommunicable, often chronic diseases that are now the most prevalent amongst older populations $(\mathrm{WHO}, 2012)$. There are concerns that without sufficient planning and investment, healthcare systems will not be able to sustain themselves and meet the changing needs of their patients (UN, 2015b). Issues of poor health among the older population are not viewed as solely a problem for older people, but are considered in view of the wider population. The UN (2015b) advocates for an approach to population ageing and healthcare that understands ageing is a life-long process and lifestyle changes at all ages are important in the prevention of non-communicable diseases, the focus needs to be on all sectors of society and not simply older people.

Concerns around the health of older people are closely related to fears around labour market issues to do with pensions, retirement, and social security and labour shortages that may impede the ability for socioeconomic development to continue in an ageing world (WHO 2012; Vos et al., 2009). One fear is that due to declining health older people will be forced to leave the workforce earlier than they would have otherwise, leaving a skills gap to be filled by the declining younger sector of society. At the same time, at present both in Aotearoa New Zealand and globally, there are recognised barriers to older people's continued participation in paid employment and as the segment of the population that is over 65 grows this will become a more significant issue (UN, 2015b; Dalziel, 
2001). There are also concerns that pension systems will not be able to cope with the growing numbers of older people, leading to reduced incomes for retired people and the financially vulnerable (Vos et al., 2009). These issues around health and labour are indicative of the fear of old age that will be discussed in the discourse section.

\section{Discourses around Population Ageing}

The awareness of population ageing discourses is central to understanding and locating this research within the realm of development studies. The discourses that I am discussing here are paradoxical - at once ageing populations are seen as successes of development, and burdens. One of the dominant discourses of development is the notion of development as progress (Potter, 2014), and this discourse is present throughout the literature surveyed here. Many authors refer to population ageing as a triumph or success of development (UNFPA \& HelpAge International, 2012; WHO, 2012; WHO, 2000; HelpAge International, 2014), which supports a view of development as progress and improvement. Population ageing is indicative of improvements in life expectancy and declining fertility rates which can be viewed as directly related to the goals of the international development community such as the Millennium Development Goals and the more recent SDGs (UN, 2015a). Declining fertility rates are a sign of gains in gender equality and reproductive rights. One of the indicators of the Human Development Index (HDI) is life expectancy, which also relates to an ageing population and an increase in people reaching old age, further supporting the notion of development as progress (Potter, 2014).

A contrasting discourse which exists in tension with 'development as progress' is 'ageing as societal burden'. Central to this discourse is the perception of ageing as a process of inevitable decline (Onyx \& Benton, 1995; Palmore, 1999; Vincent, 1999). Onyx and Benton (1995) state that "ageing is often regarded [...] as a fixed transformation [...] totally determined by the biological processes of decline 
leading to death" (p. 46). If ageing is viewed as a process of inevitable decline in terms of health and ability, the discourse that positions older people as burdens on society gains strength. This perception has shaped the way that people respond to the demographic shift that is population ageing, and the two discourses are constantly in a state of negotiation. This discomfort is evidenced in the language used in literature on population ageing. In several report titles, direct reference is made to ageing as a "crisis or opportunity" (WHO, 2000), "a celebration and a challenge" (UNFPA \& HelpAge International, 2012), or older people as a "burden or resource" (HelpAge International, 2014). The tensions between these two discourses are clear within the literature and they exemplify an ongoing struggle between progress and decline.

Older people are frequently conceptualised in terms of their economic potential or lack thereof (Asquith, 2009). Although nearly all of the cited literature highlights the importance of challenging and resisting negative stereotypes and images of older people in order to turn population ageing from a crisis into an opportunity, there is still a tendency to utilise stereotypes and negative imagery at the same time as trying to advocate for marginalised older people. HelpAge International (2014) put forth that "older people who are frail, vulnerable and no longer an economic resource should not be devalued or overlooked" (p. 17), which works to further reinforce the link between economic productivity and worth and reveals an ambivalence about the aged and their place in society. Conversely, economically unproductive people are constructed as burdens with nothing to give or contribute economically. My research challenges this narrow economic view of worth by exploring some of the multitude of non-economic ways that older people contribute to their communities. 


\section{The Rebranding of Old Age}

This section explores the changes and trends in policy around the world in response to population ageing. It examines the emergence of "active ageing" and similar terms, and links the active ageing discourse to neoliberal economics. Although in Aotearoa New Zealand the relevant policy is referred to as 'positive ageing', ideologically active ageing and positive ageing have much in common.

\section{The Evolution of the New Old}

There is no singular definition of active ageing, and it is a term often used interchangeably with phrases like healthy ageing, productive ageing, positive ageing, and successful ageing (Walker, 2015; Lassen \& Moreira, 2014; Boudiny, 2013; Foster \& Walker, 2013; Bowling, 2008; Walker, 2002). All iterations of the phrase have emerged at different times in relation to the discourse of age as inevitable decline discussed above, and have come to intertwine and overlap with each other. One of the functions of active ageing and its counterparts is to reframe older people from burdens to resources. Successful ageing was among the earliest of the terms to emerge, and as established by Rowe and Kahn (1997) it involved conceptualising older people as healthy, productive and active. Successful ageing acted in part as a response to disengagement theory, through which old age was seen as a period of withdrawal from society and relationships (Walker, 2002). The terminology of successful ageing has been critiqued because with success must come failure, and if there is a correct way to age then there must also be a way to age incorrectly as well (Walker, 2015).

Productive ageing emerged after successful ageing in the 1980s, as part of a response to dissatisfaction with the expectation that life follows a simple three point path from education on to work on to leisure (Walker, 2002). Productive ageing is closely related to ideas around economic success and failure. 
Productivity is meant in the economic sense of productive work, as evidenced by the narrow focus on "the production of goods and services" (Walker, 2002) that proponents of productive ageing promoted. Emphasis is placed on encouraging the continued participation of older people in productive work and activities. This economic connection, still relevant today, has lingered despite the everchanging terminology.

Active ageing emerged in its current form in the 1990s and early 2000s and was cemented internationally in WHO's (2002) Active Ageing Policy Framework (Clarke \& Warren, 2007). Its central tenets are around health, participation and security for older people (WHO, 2002). There are generally two approaches that active ageing frameworks take, either a narrow economic based one, or a more holistic view with room for diverse understandings of 'activity' beyond the purely economic (Foster \& Walker, 2013). The WHO (2002) policy framework is often regarded as an exemplar of the holistic approach to active ageing (for example Walker, 2015; Foster \& Walker, 2013; Boudiny, 2013). WHO (2002) clearly states that active ageing has a place for "people who retire from work and those who are ill or live with disabilities" (p. 12). On the other hand, the OECD views active ageing largely in economic terms, with a focus on older people and their contributions to the workforce and economy (Taylor, 2011), which exemplifies the purely economic approach to active ageing.

However, when arguing why policymakers should take on the suggestions even WHO turns to economic arguments to persuade: "there are good economic reasons for enacting policies and programmes that promote active ageing in terms of increased participation and reduced costs in care" (p. 17). Policymakers are urged to consider how better health together with changes in retirement policies will lead to more people staying in work for longer, increasing their contributions to public revenues coupled with reduced healthcare costs (WHO, 2002). This suggests that one of the dominant focuses of active ageing policy in 
its current form relates to economic concerns rather than a whole of life holistic approach (Boudiny, 2013). This is further reinforced with the ongoing referral to older people as 'resources' throughout active and positive ageing documents both internationally and in Aotearoa New Zealand (Dalziel, 2001; WHO, 2002).

\section{Neoliberalism and Ageing}

Neoliberalism is an ideological approach to economics that focuses on individual freedoms and the importance of 'the market', whilst seeking to deemphasise the role of the state in the economy (Mooney \& Evans, 2007; Conway, 2014). Key features of a neoliberal approach include the reduction of expenditure on social services by the government and the privatisation of public goods, leaving the state with the role of regulating trade and capital flows (Conway, 2014). This is indicative of the promotion of a productive society which is set up to "maximize profits and efficiency" (Conway, 2014, p. 107). Neoliberal influences can be seen in the operations of international organisations such as the World Bank and International Monetary Fund (IMF), perhaps most clearly in their utilisation of Structural Adjustment Programmes (SAPs) for developing countries (Conway, 2014; Mooney \& Evans, 2007). Neoliberalism has been referred to as a term for critics (Castree, Kitchin, \& Rogers, 2013), and I am indeed critical of neoliberal approaches and the impact they have on vulnerable groups in society (Asquith, 2009). Aotearoa New Zealand, along with Chile, Britain and the USA, introduced neoliberal policies in the 1980s and continues to do so into the present day. The impact of the neoliberal political ideology held by the present government on older people in Aotearoa New Zealand has the potential to have limiting and negative effects on their choices to live how they wish, despite individual freedoms being an integral part of neoliberal ideals. A focus on productivity puts a magnifying glass onto those deemed unproductive. 
Policies aimed at rebranding ageing are closely linked with neoliberal ideals such as economic productivity and individual responsibility, and the shift from welfare states to market based economies (Biggs, 2001; Walker, 2015; Mendes, 2013). Biggs (2001) has detailed this shift and what it means for older people, the key users of healthcare and social services. Along with this change in ideology has come a change in the stories that are told about older people and old age. The narrative from policy-makers and governments was formerly one of dependency and passivity (Biggs, 2001), but in order for neoliberal policies to have some chance of success in shifting the responsibility for welfare from the state to the individual, this narrative needed to change. Biggs (2001) details how the narrative of dependency coupled with social policy acted as a self-fulfilling prophecy, with economic mechanisms ${ }^{1}$ working to create situations of dependence.

According to Walker (2015), neoliberalism is ever-present in the discourse around active ageing and works to reduce 'activity' down to simply working longer. While Boudiny (2013) finds active ageing to have the potential to challenge such purely economic focuses of ageing, she finds that - rather than challenging them - the concept of active ageing actually mirrors them by using economic justifications for adopting active ageing policies. As discussed above, there are attempts by actors such as WHO to promote a holistic view of ageing through policy frameworks, but economic value is frequently brought in as a justification. This indicates that further research needs to be conducted to explore the efforts of people to resist and challenge the narrow economic definitions of active/positive ageing. This thesis contributes to those efforts through its focus

\footnotetext{
${ }^{1}$ Such as "the forced expulsion of older people from the workforce" and "the manipulation of vulnerable older people as if they were commodities in a welfare market" (Biggs, 2001, p. 306).
} 
on older volunteers and the relationship between volunteering, rather than paid work, and positive ageing.

\section{Active Ageing and Exclusion}

The literature surrounding the rebranding of old age both draws upon and critiques various stereotypes and discourses in order to support new policies and approaches toward population ageing. As mentioned above, within active ageing literature and in particular policy documents, older people are often referred to as a resource, an economic term. Active ageing also implies physically active older people, promoting a narrow understanding of what 'health' looks like. Although intended to positively reframe old age, this shift in terminology may also work to exclude and marginalise those who do not fit with the positive images of healthy, active ageing. For example, Ranzijn (2010) highlights the implication that active ageing entails "productive involvement in social activities, presumably making a positive contribution to society" (p. 717), which is not possible for all older people. Zimmermann and Grebe (2014) found that attitudes towards older people had changed along with the advent of positive ageing policy in Germany, but that negative stereotypes had simply shifted up to those aged 80 and older. Concerns about exclusion and active ageing can be addressed by the collective action of governments, community organisations and individuals.

\section{Positive Ageing in Aotearoa New Zealand}

Aotearoa New Zealand is one of many countries experiencing population ageing and the PAS (Dalziel, 2001) is one of the key responses to this demographic shift.

The New Zealand Government has an Office for Senior Citizens within the Ministry of Social Development, which at the time the PAS was introduced was 
called the Senior Citizens Unit. The PAS was introduced in the early 2000s within the neoliberal policy climate discussed above. The strategy is still used in 2016 and is intended to be a living document, meaning that it is continually updated and open to change. In developing the PAS through consultation with the public, the Government decided to take an approach which acted to dismantle the "barriers that segregate older people from the rest of society" (Prime Ministerial Task Force on Positive Ageing, 1997, p. 1). The PAS acts a guideline for developing any policy in government that will affect older people either at present or in the future, and as a guideline for local councils to create their own positive ageing policies. The document emphasises the importance of older people experiencing ageing as "a positive and productive phenomenon" (Dalziel, 2001, p. 11), and although the PAS speaks to more than just the economic benefits of positive ageing, the underlying tone is one of an economic focus (Davey \& Glasgow, 2006). For example, the foreword of the PAS includes a quote referring to older people as an "immense resource" to be "harnessed" in order for New Zealand to be able to compete against other countries (Dalziel, 2001, p. 3).

The Wellington City Council (2012) has the PAP which builds on the PAS. The policy aims to increase "economic growth and vitality" (p. 2) by recognising and making the most of the power of older people in Wellington. Both the PAS and the PAP discuss the benefits to individuals that stem from a positive ageing approach, but on the whole the key benefits relate to continued economic growth, and the emphasis on benefits moves from the individual, their families and communities, to the country (or city) at large. Davey and Glasgow (2006) discuss the PAS in detail and find that the rhetoric of positive or active ageing utilised by the New Zealand Government requires "ongoing participation in productive activity, with a particular emphasis on extending labour force involvement" (p. 26) which raises concerns about the place for older people within Aotearoa New Zealand society who are unable to or do not wish to participate in these ways. 


\section{Older Volunteers}

This final section of the literature review explores the literature relating to older volunteers, using reciprocity, care and empowerment as lenses through which to interpret volunteering by older people. Throughout this section connections are made to the discourses around ageing discussed above, as well as the need for communities to respond to neoliberal policies that have forced cutbacks in social service provision.

Both the PAS and the PAP share the same Positive Ageing Goals (see Figure 1) (with the exception of goals relating to rural New Zealand, which are not relevant in Wellington). The PAS and PAP make reference to the benefits associated with volunteering for older people and their communities as seen in the shared goal, Goal 10: "Increasing opportunities for personal growth and community participation". The actions associated with this goal, 10.3 "encourage utilisation of the experience and skills of older people" and 10.4 "promote and support volunteers and their organisations" relate directly to volunteering (Office for Senior Citizens, 2008). By linking personal growth with community participation, the reciprocal nature of volunteering is emphasised. The literature suggests a tension between government and individual expectations of volunteering and 'positive' or 'active' ageing that I will be further exploring in my research. 
1. Income - secure and adequate income for older people.

2. Health - equitable, timely, affordable and accessible health services for older people.

3. Housing - affordable and appropriate housing options for older people.

4. Transport - affordable and accessible transport options for older people.

5. Ageing in the Community - older people feel safe and secure and can age in the community.

6. Cultural Diversity - a range of culturally appropriate services allows choices for older people.

7. Rural Services - older people living in rural communities are not disadvantaged when accessing services.

8. Positive Attitudes - people of all ages have positive attitudes to ageing and older people.

9. Employment Opportunities - elimination of ageism and the promotion of flexible work options.

10.Opportunities for Personal Growth and Participation - increasing opportunities for personal growth and community participation.

Figure 1: The 10 Positive Ageing Goals. Source: Office for Senior Citizens, 2014.

Volunteering

Volunteering is central to this research project and it is important to clarify the definition of formal volunteering that I have adopted in my approach. Warburton and McLaughlin (2005) make a distinction between formal volunteering and informal volunteering with the latter referring to "the myriad ways that people contribute to their families, friends, neighbourhood and the community" (p. 716). Formal volunteering is voluntary work that is structured and occurs within an organisation, whereas informal volunteering takes into account unstructured acts, "little kindnesses" (Warburton \& 
McLaughlin, 2005, p. 720) undertaken of an individual's own accord. However, further differences in understanding and conceptualisations of volunteering can be seen in the Aotearoa New Zealand context. Mahi aroha is the Maori phrase which most closely translates to volunteer work, and is defined as "work performed out of love, sympathy or caring, rather than for financial or personal reward" (Office for the Community and Voluntary Sector, 2007, p. 13). This understanding of mahi aroha is but one of a multitude of understandings of volunteering that exists within Aotearoa New Zealand's diverse populace. Other understandings have been described in in-depth qualitative research carried out to explore the conceptualisations of volunteering and cultural obligation held by members of Pacific communities in Aotearoa New Zealand (Tamasese, Parsons, Sullivan, \& Waldegrave, 2010). In traditional Pacific cultures, the concept of 'volunteering' has no direct translation, as it is a foreign concept. However, there are traditional activities that Pacific peoples carry out that are conceptually close to volunteering, though these are not necessarily regarded as volunteering (Tamasese et al., 2010). As will be discussed in Chapter Three, my research has adopted a formal, Pākehā understanding of volunteering although throughout the interviews the research participants revealed informal aspects of volunteering as well. The following sections help to characterise the formal understanding of volunteering that this research has adopted.

\section{Volunteering and Reciprocity}

The reciprocal nature of volunteering is well-documented (Barlow \& Hainsworth, 2001; Warburton \& McLaughlin, 2005; Narushima, 2005). Reciprocity can be defined as being "a social exchange of benefits with each party expecting some return" (Stephens, Breheny, \& Mansvelt, 2015, p. 23). When reciprocity is linked with volunteering, it is understood that the volunteer gains some personal benefit through their act of giving. With regards to older people, 
this two-way relationship is complex and extends beyond simplistic dichotomies of give and take. For some older volunteers there is a moral imperative to contribute and this is tied to notions of productivity and responsibility (Stephens et al., 2015). In this research project I aim to explore the motives that older people give for their decision to engage in volunteering and whether they view it as something they need to do or something they want to do or a combination of the two.

Furthermore, Stephens et al. (2015) express the complicated nature of the interrelationship between neoliberal economic policies and reciprocity as a societal norm. Amongst discourses emphasising productivity, participation and contribution to society through work or work-like activities, reciprocity holds a deeper meaning for older people for whom value is placed in their ability to continually contribute (Stephens et al., 2015). Within the neoliberal social structure, a moral imperative to contribute is placed on older people, because if you are receiving any kind of support it is important to give back (Stephens et al., 2015).

Another view of reciprocity that comes through in the literature is more closely related to the act of volunteering itself rather than a general imperative to contribute. Research relating to the varied motivations of older volunteers has identified reciprocity as an important lens through which to view their motivations (Barlow \& Hainsworth, 2001; Narushima, 2005; Wiles \& Jayasinha, 2013). Older people volunteer for a vast variety of reasons but running through these motivations is a sense of give and take (Narushima, 2005). There are personal benefits to volunteering that are closely linked to 'giving back' and 'helping out in the community'. For example, if someone helps out in their community they are benefiting the community and themselves by making it a better place to live. 
Governments are interested in the promotion of volunteering for multiple reasons as well, in part - arguably - because with the cutbacks in social services there are people needed to fill the service gaps (Lie, Baines, \& Wheelock, 2009). Along with this, are the well-documented health and social benefits of volunteering to volunteers (Stephens et al., 2015), thus reducing the reliance of older people on healthcare systems. In relation to my research this notion of reciprocity and motivation is useful in analysing the reasons participants give for their continued participation in voluntary work, and comparing or contrasting them with reasons promoted by local and central government.

\section{Volunteering and Care}

Care for place is a concept put forth by Wiles and Jayasinha (2013) as useful in making sense of some of the motivating factors for participation in voluntary work undertaken by older people. This understanding of care, which expands on the usual definition as "the provision of practical or emotional support (usually to another person)" (Wiles \& Jayasinha, 2013, p. 94) moves from caring for other people to caring for communities and neighbourhoods.

The link between care and volunteering has been widely discussed as one of the key motivations driving older people to make ongoing contributions to their communities (Wiles \& Jayasinha, 2013; Rawsthorne, 2012, Hardhill \& Baines, 2009). This care for community is said to be expressed alongside other elements of care, such as caring for friends or family members (Wiles \& Jayasinha, 2013). In undertaking these various acts of care, Wiles and Jayasinha (2013) argue that older volunteers are able to resist "notions of older people as passive, dependent and marginalised." (p. 100). However, the argument of Wiles and Jayasinha (2013) is balanced precariously between, on the one hand recognising and honouring the contributions that older people make to their communities, and 
on the other hand being wary of being construed as advocating the removal of responsibility for care from the government (Lie et al., 2009). This anxiety is pertinent when considering the shifting discourses of responsibility discussed above in relation to neoliberal policy responses to population ageing.

\section{Volunteering and Empowerment}

Empowerment is defined by Gibson and Woolcock (2008) as "the process of enhancing individual or group capacity to make choices and transform those choices into desired actions and outcomes" (p. 152). In the context of resisting negative stereotypes around old age, empowerment through action is key to challenging the dominant narratives. Further to Gibson and Woolcock's (2008) definition, Castree, Kitchin and Rogers (2013) view empowerment as the increased capacity of an individual to "shape their own life and bring about social change" (p. 126), a definition that is recurrent in the literature on older people and volunteering (Kam, 1996; Onyx \& Benton, 1995; Barlow \& Hainsworth, 2001). Empowerment is relevant due to my post-development perspective and the importance of recognising the agency of individuals and their ability to make their own choices and change their own lives. Recognising agency works to shift understandings of older people from viewing them as a passive group that things happen to, to active individuals taking part in society. Kam (1996) is clear on the positive impacts on individuals and society that will flow on from the empowerment of older people. In particular, Kam (1996) highlights the potential for the empowerment of those in long term care, those often portrayed as the dependent and frail elderly that governments and policymakers fear as a potential economic burden. Rather than viewing older people in long term care as existing separately from the community and society, Kam (1996) advocates including these older people in community and political participation. This inclusion of the most vulnerable older people speaks to the balance and resilience 
that Wiles and Jayasinha (2013) seek to emphasise in finding the middle ground between overly positive and overly negative views of older people. Of central importance here is that the inclusion must be meaningful, and not tokenistic. I argue that the tokenistic inclusion of older people in community participation stems in part from stereotypical beliefs that regard older people as passive and helpless.

In this research I work to challenge disempowering stereotypical beliefs and honour the contributions made by older volunteers to their communities in Wellington (I take contribution in this sense to mean expressions of care, rather than an economic meaning). The language used in some of the academic literature on volunteering is condescending to the efforts of older volunteers even as it aims to celebrate them, for example Barlow and Hainsworths' (2001) call for older volunteers not to miss out on the "'pat on the back' they so richly deserve" (p. 215). This kind of tokenistic recognition illustrates the strength of stereotypes in shaping views and expectations of older people even among those who are advocating for the breakdown of those stereotypes and the empowerment of older people. My research responds to Wiles and Jayasinha's (2013) call for future researchers to work towards "further [understanding] and honour[ing] the multiple ways in which older people can, and do, care for the places in which they are ageing" (p. 100).

\section{Conclusion}

Anxieties about the challenges of population ageing dominate discussions of how best to respond to this demographic shift in order to not stifle the potential for further socioeconomic development. Active ageing policies have worked to reduce those anxieties by portraying ageing in a positive light and emphasising productivity and contributions that can be made by older people, but in turn it is difficult for this positive framing to capture the complexities of old age, which 
can be both a positive and a negative experience. Volunteering is promoted as a positive way for older people to spend their time, but the reasons that governments promote this are often at odds with the reasons and motivations that older volunteers themselves give. Using empowerment, care, and reciprocity as lenses for analysis in this research I explore the motivations, benefits, challenges and coping strategies discussed by older volunteers in Wellington as they navigate their own positive ageing experiences. This will address current gaps in the literature whereby the New Zealand Government and Wellington City Council rely on quantitative rather than qualitative data when monitoring and evaluating the progress of their respective strategy and policy. This focus on the voices of older volunteers will allow me to contrast lived experiences with expectations from policy documents. 


\section{Chapter Three: Methodology}

\section{Introduction}

In this chapter I explore the methodology and methods employed in this research project. I start by locating myself within the research through an exploration of my worldview and positionality, and then expand on my choice of a qualitative research methodology. I then discuss the methods used in data collection and analysis. I conclude the chapter with an exploration of the ethical considerations and limitations of this research project.

\section{Worldview}

I have approached this research with a social constructivist epistemological stance. Throughout the research process meaning is understood to be something that is not discovered, but co-created through social interactions between myself and research participants, my supervisors, and others (Jaffe \& Miller, 1994).

Along with this epistemological standpoint, I utilise hopeful and constructive theories of post-development in my understanding of this research (McGregor, 2009). By focusing this Development Studies thesis on Aotearoa New Zealand, a 'developed' country, rather than in a country classed as 'developing' or 'Third World', I am problematizing the notion that development is something that only exists "over there" (Jones, 2000, p. 237). In focusing the study in my own community of Wellington, where I have lived for the past 6 years, I am heeding Esteva and Prakash's (2006) call for "the replacement of 'global thinking' with 'local thinking'"' (p. 278). I have also made the decision to privilege the voices of older volunteers speaking about their lived experiences, taking a bottom-up approach rather talking to volunteer co-ordinators or council workers involved in management and policymaking. In choosing this bottom-up approach, I acknowledge that "people have always been the agents of their own 
development, sometimes working alone, sometimes through collective endeavour" (McGee, 2002, p. 92). The nature of this project entails an exploration of how people's agency influences their development outcomes.

My focus on volunteering and rejection of wholly mainstream economic conceptualisations of the value and productivity of voluntary work ties in with Gibson-Graham's (2007) work on diverse economies and a hopeful, imaginative post-development agenda. Through challenging the reduction of voluntary work to its economic value, and encouraging multiple stories to be shared in relation to motivations and experiences of volunteering, I am contributing to bodies of work in which "multiple temporalities and storylines are untethered from one linear narrative" (Gibson-Graham, 2007, p. 151).

\section{Positionality}

Creswell (2014) emphasises the importance of the social constructivist researcher placing themselves firmly within their research, in order to "acknowledge how their interpretation flows from their personal, cultural, and historical experiences" (p. 8). Positionality is important to consider in relation to research because of the insight that can be gained by reflecting on how the perspectives and positions of the researcher and those participating in the research can influence outcomes. It is important that I situate myself within this research to be clear about the extent to which my positionality and life experiences have shaped my approach at all stages of the research process (Mason, 2002). Acknowledging my position in this chapter serves to contextualise for the reader how I have designed and carried out the project. The findings of social research "will only ever provide a partial picture of the social world being interrogated" (StewartWithers, Banks, McGregor, \& Meo-Sewabu, 2014, p.62), and my positionality is one factor that contributes to the partial nature of my findings. 
Positionality has been described by Chacko (2004) as "aspects of identity in terms of race, gender, caste, sexuality and other attributes that are markers of relational positions in society" (p. 52). In terms of "other attributes" that are of particular interest here, my age is central to my position within this research. Although I reflect here on pertinent elements of my positionality that influenced my research decisions and interactions, I am aware that a single positionality statement cannot cover the complexity of what is always an ever-shifting position (Merriam et al., 2001).

I am a 24 year old Pākehā female postgraduate student, from a middle-class background. To illustrate the relational nature of positionality, during a prior research project that involved working with refugee-background youth at a local high school I was regarded as an 'older researcher'. At present, I am now a 'younger researcher', despite being chronologically older than before. My age positions me as an outsider to the group of people that I am interacting with, despite any other similarities in background and experience.

Jaffe and Miller (1994) state that our understandings of the "world of the aged" are influenced by our positionality, as well as "our own experience of aging" (p. 53). Witnessing the decline in mental and physical health of my maternal grandmother over a long period of time has coloured my view of ageing, and expectations of older people. My experience of ageing within my immediate family is often at odds with the 'active' or 'positive' ageing discourse, and the realisation that this experience was not universal was one of the factors that sparked my interest in this research topic and learning about other experiences of positive ageing. Family history also provides insight into the personal definition of volunteering that has shaped my approach to this research. Stories of my maternal grandparent's continued community service throughout their 70s and 80 s, along with my own involvement with voluntary organisations such as English Language Partners, combined with my upbringing, have shaped a 
formalised view of volunteering, the effects of which will be seen later in this chapter.

Positionalities interact and shift depending on the situation, and my position as a young woman played a definitive role in determining how interviewees chose to respond to my questions, and the information that they chose to disclose (Leontowitsch, 2012). My understanding of the interviewees' positionalities also impacted on how I interacted with them and the language and behaviour I displayed during interviews, taking cues from their behaviour to inform my own actions.

\section{Qualitative approach}

Qualitative approaches to research seek to understand the social world, the lived realities of particular people or groups, and "the goal is to both understand and find meaning, and perhaps bring about change" (Stewart-Withers et al., 2014, p. 60). This desire for understanding has shaped my decision-making in terms of methods for data collection and analysis (discussed below), and the way I have chosen to present the research findings in a manner that privileges the voices of the research participants.

My primary aim in this research project is to explore and understand the nature of the relationship between volunteering and positive ageing. One of the frustrations that I encountered at the proposal stage was the lack of qualitative data linking positive ageing to volunteering. The New Zealand Government's PAS indicators relating to volunteering refer to quantitative measures and economic measures that did not provide answers to my questions. In order to gain a deeper understanding of this phenomenon, I decided to utilise a qualitative research approach. By taking this approach, I have been able to gain insight into the social world of the research participants, including their 
"understandings, experiences and imaginings" (Mason, 2002, p. 1) about volunteering and positive ageing.

\section{Methods}

\section{Recruitment and sampling:}

I took a multi-faceted approach toward recruitment to increase the likelihood of finding interested participants that were of varied backgrounds. My recruitment approach involved a mixture of online and in person communications to Wellington-based community organisations, along with a poster that was displayed on community noticeboards, in 'volunteer areas' of voluntary organisations, and in the lunchroom of my workplace ${ }^{2}$. Although I started the recruitment process by emailing as many organisations as I could, I turned to in person visits to introduce myself and my research as inspired by the relationship building described by Wiles and Jayasinha (2013) in their research about older people and care for place. Wiles and Jayasinha (2013) describe personal connection as important in building trust and relationships with research participants. Although my research differs from theirs in that they had a longer time period in which to build these relationships, I still appreciate the importance of trust-building in qualitative research. After carrying out a few interviews, participants started to put me in contact with other volunteers whom they believed may be interested in taking part, utilising a snowball effect to gather further research participants. This combination of recruitment techniques resulted in a total sample of 11 current volunteers, 1 former volunteer, and 1

\footnotetext{
${ }^{2}$ My workplace is a hardware and home goods store, not directly linked to older people or volunteering. However, there are a large number of people working there of a range of backgrounds, some of whom were kind enough to let their friends or family know about the research, thus extending the reach of the poster.
} 
husband of a volunteer who offered his thoughts towards the end of an interview. There were 5 men and 8 women, and their ages ranged from 67-80. The sample was ethnically homogenous, largely made up of New Zealand European/ Pākehā with two participants who had migrated from the United Kingdom and the United States. Table 1 shows the range of volunteer activities that participants were actively engaged in.

\begin{tabular}{|l|l|}
\hline Voluntary roles & Participants \\
\hline The Arts & P2, P5, P6, P7 \\
\hline Guides & P1, P3, P9, P10 \\
\hline Community safety & P5, P8 \\
\hline Op shops & P4, P11 \\
\hline Research & P12 \\
\hline Animal care & P4, P12 \\
\hline
\end{tabular}

Table 1: Voluntary roles of the research participants.

Barbour (2008) asserts the importance of researchers asking themselves "Who might I be leaving out?" (p. 53) which is a question that I reflected on as the interview period came to a close. The views of Māori, Pasifika, and minority ethnic groups are missing from this research. In part this absence could be due to my recruitment techniques, my personal definition of volunteering and the way that I have conceptualised volunteering in this research in a formal manner. I acknowledge that there are varied and multiple ways of conceptualising volunteering, but for the purposes of this research I have focussed on formal as opposed to informal volunteering.

The criteria that I initially applied for recruitment were: the person be aged 65 or over, and be an active volunteer in the Wellington region. As is often the nature 
of qualitative research, I learned that I had to evolve this criteria and make different decisions about inclusion over time. One research participant who contacted me, for example, had recently stopped volunteering, so did not meet the criteria of being an 'active volunteer'. However, his experiences of volunteering, particularly in relation to the research questions around challenges and barriers to volunteering, provided valuable insight into challenges that I may not have heard from people satisfied with their position.

It is impossible to know how many people saw a poster or email inviting them to participate in the research and declined to get in contact either because the terminology used ('older volunteers') discouraged them or they were younger than the minimum age stated. As I reflected on the recruitment process I felt a growing sense of discomfort with using 65 as a minimum age for participants. 65 is the age of eligibility for state-paid superannuation in Aotearoa New Zealand, and is commonly used as a demographic marker. However, this use of chronological age stands in contrast to studies that have conceptualised age as a social construct (for example Wiles \& Jayasinha, 2013). After posters had been emailed and put up in public places I began to feel that putting a minimum age in the recruitment material was the wrong approach, as people should be free to self-identify as an older volunteer. However, a comment from a participant prior to the start of an interview highlighted the value of including an age as a reference point for potential participants. The participant told me that she did not consider herself to be an 'older' volunteer, but seeing the minimum age listed led her to realise that perhaps I would be interested in speaking to her after all.

\section{Semi-Structured Interviews}

I made the decision to carry out one-on-one semi-structured interviews with older volunteers in Wellington as this research project is centred on questions 
relating to "knowledge, views, understandings, interpretations, experiences, and interactions" (Mason, 2002, p. 63) that qualitative interviewing is well-positioned to explore. Prior to conducting interviews I first designed an interview protocol with a series of interview questions closely relating to my research questions and assorted suggestions of prompts for each question. This involved a lengthy process of drafting and re-drafting open-ended questions, and this iterative process continued throughout the interviews as I discovered new ways of asking about experiences and views. In developing the interview protocol(s) I was able to draw on questions and approaches utilised in other studies relating to ageing, volunteering and community development (such as Rawsthorne, 2012; Wiles \& Jayasinha, 2013; Narushima, 2005).

The varied experience of the interviews led to a rich and enjoyable data collection period. As I became more experienced and less nervous as an interviewer, I was able to focus more on the notion of the 'interview as conversation' approach rather than the imaginary of 'serious research interview' that I initially harboured. As an example of the evolving nature of the interview questions from my interview protocol, one question used in earlier interviews was rather clumsily phrased as "what stereotypes about ageing are you aware of?" This question elicited thoughtful responses from the participants, but often after a period of confusion or requests to rephrase. In later interviews I rephrased this question as "how are older people portrayed in New Zealand (media/society)?" which was followed with much less confusion and was less leading. The interview protocol was used as a guide, perhaps more strictly in earlier rather than later interviews, but the same questions were not asked in each interview. Some participants answered the first three questions whilst responding to question number one, and others shifted from topic to topic naturally. Having the protocol as a guide and not a script was beneficial in ensuring that key 
questions or topics were explored with each participant, tailored to their personal experiences and responses.

\section{Interviews and Power}

I agree with Stewart-Withers et al. (2014) in their acknowledgement that the power relations between researchers and research participants are far from straightforward. I cannot presume to fully understand the nature of the power relations between myself and the participants in this research project, however I am able to reflect on aspects of my positionality and life experience that may have informed our interactions.

Within this research project power relations cannot be simply reduced to powerful university researcher and less powerful research participants. I come from a family where 'respect your elders' was a common refrain, but simultaneously I am a 'young person' living in a society that privileges youth. In terms of my research experience, these conflicting aspects served to complicate my understandings of power.

As a Pākehā, middle-class postgraduate researcher I recognise that I am able to make decisions about what questions are asked, to whom, and in what way answers are interpreted and published. One strategy that I used in attempting to negotiate uneven power relations was making it clear when arranging the interviews that I was happy to travel to whichever location was preferred by the interviewee, and leaving the decision of location open to them (Elwood \& Martin, 2000). Interviews thus took place in a range of locations, from participants' homes to cafes around Wellington. Only one participant chose to be interviewed in his place of volunteering.

Participants illustrated the two-way power relationship between researcher and participant in a number of ways: they exercised power through interviews in the 
information that they chose to share with me, and challenged and corrected me when they felt I had misrepresented their views. There is also power to be observed in reticence or refusal to elaborate on a response to a question.

\section{Analysis}

Analysis began during the interview process as an iterative act of reflection and adaptation. After each interview I would write a reflection in my research journal containing observations on the interaction between myself and the participant. I also kept a list of codes and topics as they occurred to me following interviews. Transcription of interviews involved multiple reviews in order to pick up on subtleties such as tone of voice and emphasis on certain words or sentences that might impact the meaning or understanding (Barbour, 2008). Once the transcripts were complete I sent a summary of the interview to participants who had indicated on the consent form that they wished to receive one. Participants were then able to confirm, deny, clarify or add new thoughts to the interview if they so wished. After each interview I also confirmed my contact details and willingness to be contacted if there were additional thoughts that they wanted to share, which was another effort to minimize power inequalities.

I have used a thematic analysis to read the data in literal, interpretive, and reflexive ways (Mason, 2002). I chose to undertake thematic analysis rather than discourse analysis because a thematic analysis holds the freedom to explore both practical and discursive elements of the data. As suggested by Narushima (2005), I first analysed each transcript alone, deriving some basic themes and codes. As more codes emerged I returned to earlier transcripts to recode with new codes in mind. In support of this approach, Rubin and Rubin (1995) state that the lessons learned from coding later interviews can provide insights into themes and ideas that were unclear in earlier interviews, gradually building up understandings of the data. Although I at first intended to use data analysis software, once I actually had the 12 interview transcripts completed my approach to coding became more 
organic and tangible, with a system involving a code book, and different coloured pencils. This process of analysis led to the development of a framework of three key themes - volunteering, positive ageing, and representations and stereotypes - through which I could present the results (Stewart-Withers et al., 2014).

\section{Ethical Considerations}

Confidentiality of participants was a key ethical consideration in this research. This was important due to the sensitive and personal nature of some aspects of the research, and there was a clear need to ensure that participants' felt they could discuss institutional barriers or challenges relating to volunteering without fear of repercussions. Not every participant held critical views that they shared with me relating to the organisation(s) that they volunteered with, but those who did made specific reference to the fact that 'no names were being named', and their identities would not be publicly shared. This has led to the anonymization of participants' associated organisations, as well as the use of 'Participant $X^{\prime}$ ' when referring to them throughout this thesis.

Barbour (2008) argues that it is important think about the safety of the researcher as well as research participants when considering ethics. When attending interviews at private homes, I would let my flatmates or officemates know details of where I was going, and what time I was expected back home or on campus.

I was granted ethical approval (approval number 21887) from the Victoria University Human Ethics Committee, which was necessary to proceed with the project. The Approval Memorandum, Participant Information Sheet and Consent Form are included in Appendix One. Participants were given the Information Sheet and Consent form prior to the start of the interviews and were asked to grant permission for their interviews to be recorded. Participants were also given 
the option of receiving a summary of their interview to confirm I had accurately understood their responses and a summary of the results of the overall research.

\section{Limitations}

A crucial limitation of this research that needs to be considered is the focus on positive ageing. A positive conceptualisation of ageing can counter negative stereotypes, but can also limit discussion of a more nuanced view of ageing and volunteering. At times research participants would allude to negative experiences but say something along the lines of "oh but you're not interested in that, because this is about positive ageing", which would then lead to attempts by me to explain that I really would like to hear about both positive and negative aspects of their volunteering experiences. I have limited control over how other people interpret the aims of the research, and positive ageing is a term with powerful connotations.

Another limitation (discussed above) is the definition of volunteering that has shaped and been shaped by an ethnically homogenous sample. The small sample size is also not representative of the population at large, limiting the ability to extrapolate the findings, although they can be used as a starting point for further research.

\section{Conclusion}

In this chapter I have expanded on aspects of my positionality, worldview, and qualitative approach that have shaped the design and carrying out of this research project. Positionality, reflexivity and power are key concepts that have guided my understanding of the research process and interactions between myself and the research participants. Flexibility, an iterative process of reflection and continual learning coupled with a logical, thematic approach to data analysis 
allowed for the creation of a framework to assist in communicating my understandings and interpretations of the data. 


\section{Chapter Four: Findings}

\section{Introduction}

In this chapter I present the findings of this research project as they relate to the research questions set out at the start of this thesis. The chapter is divided into three main sections: volunteering, positive ageing, and representations and stereotypes. Each of these sections contains subsections relating to key themes which emerged during the interview process. Combined, these research findings present an answer to the primary research question guiding this project: What is the nature of the relationship between volunteering and positive ageing? Quotes from the participants are used to illustrate and emphasise these key themes.

\section{Volunteering}

In this section I will explore the key findings of this research project as they relate to the overarching theme of volunteering, organised into the following four subsections: motivations, skills and knowledge, challenges and barriers, and organisational support. In elaborating on these themes, I am responding to the following research questions:

-What is motivating older people to volunteer in their communities?

-What skills and knowledge are older people bringing to and gaining through their voluntary work?

-What challenges and barriers to participation in volunteering do the older volunteers identify, and what solutions do they put forward to address these?

Volunteering has been an integral part of life for all of the volunteers interviewed for this project. Over forty different voluntary roles past and present were raised in the interviews by the twelve participants who were volunteers. Some of the 
volunteers worked in more than one role at a time, and had dedicated years of service to their chosen organisations. A common occurrence in the interviews was the recollection of voluntary roles that the volunteer had either forgotten about until they started to reflect on the themes of this research project, or had not thought of as volunteering until our discussions during the interview. Personal definitions of volunteering differed from the definition of formal volunteering that I utilised when formulating the research questions and carrying out the recruitment process of this project. This meant that though most of the volunteers fit the definition of formal volunteers, there was also a wealth of informal voluntary work discussed as well which is outside the scope of this research project but should be recognised.

\section{Motivations}

Discussions of motivations for volunteering emphasised the reciprocal nature of voluntary work, and the volunteers acknowledged that this was something they did for their own benefit as well as the benefit of others and the wider community. Motivations varied among the volunteers, but can be grouped according to the subheadings below.

\section{It's the way I was raised:}

Many of the volunteers referred to the way they were raised by their parents as one of the reasons they were volunteers today. At times this was a general imperative to give what they could to others, or a general belief in service, "this is the way we were brought up [...] it's always been part of my life, and my profession too" (P12). In one case, the voluntary work of a son for a counselling service echoed that of his father, who had been a volunteer for the Samaritans during his childhood. The motivations for volunteering came in part from seeing it carried 
out by their parents throughout their lives, and being taught from a young age that it was the way things were done.

Giving back:

Participants articulated a feeling that volunteering was something that they believed they should do. It was almost taken for granted that they would volunteer, "oh just a feeling that one should give back" (P6), and often this was linked to specific skills that they had developed over their lives through study and work, "here I am knowing how to do these things, what'll I do with it?" (P6). On the other hand, some of the volunteers emphasised the point that people did not need to have specific skillsets in order to be a volunteer, just a willingness to contribute and the time to give: "So I'm not sure but I will do something because I have time, I have good health, I have the ability to go up and down stairs [laughs] a lot. And yeah I feel I should do something in the community" (P7). This sentiment was phrased carefully by one volunteer, "I felt like there was something I could do for other people, it wasn't that I had something to give, it was something I was able to do" (P9). Here, she illustrates that she was not trying to put herself on a pedestal, but rather show volunteering is an activity that many people could do as well.

The community has a need:

The volunteers called attention to the needs of their communities around Wellington as a key motivation for volunteering and, as shown above, saw themselves as well-placed to be able to address those needs: "It's not a difficult thing to do, if you have a car and you've got the time to do it. It's just a community thing, yeah, that needs to keep going" (P7). One volunteer moved from volunteering with her church into a more outward facing role in the wider community. Her family circumstances gave her an awareness of the organisation she chose as a place 
within the community that "could do with some help" (P1). Needs within the community ranged from the needs of vulnerable people to more generally the needs of cash-strapped organisations with a major reliance on volunteers.

\section{Enjoyment:}

All of the volunteers expressed their enjoyment of their roles as a motivation for continuing to volunteer, which will be discussed in more detail in the Positive Ageing section of this chapter. For some of the volunteers, at least one of their roles was directly related to activities they enjoyed in their leisure time, such as theatre, singing, fostering animals or working with art. The volunteers were combining their voluntary work with their passions and saw this as "the best of both worlds" (P4), which again illustrates the reciprocal nature of the volunteering described.

Personal development:

Personal development is one of the motivations for volunteering that was put forward by some of the participants. Engaging in voluntary work acted as a way of staying socially and physically engaged in the community. This demonstrates the personal benefits that the volunteers attributed to their voluntary work, and will also be discussed in more depth in the Positive Ageing section of this chapter. For these volunteers, volunteering fulfilled a need within themselves as well as allowing them to address needs in their communities:

"I'd like to think that you grow old feeling useful and making some positive contribution to the place because, you know, I'm nearly 70 and I believe I'm mentally active, and sitting at home looking at the walls is boring, it's boring [...] [it gives you] a feeling that you're still an active part of the community, really" (P8). 
For some of the volunteers, being in a position where they felt themselves beginning to withdraw from their communities provided the motivation needed to re-engage through voluntary work, as illustrated by Participant Five:

"It got me out of a place in my life where I was a little bit stuck as a person, sort of feeling like I was caught at home, not getting out, and I just sort of felt like I wasn't relating to the community much you know, so that sort of got me moving really in my life".

\section{Skills and Knowledge}

This section covers both the skills and knowledge that the volunteers have brought to their voluntary roles, as well as skills and knowledge that have been developed during their time as volunteers. For most of the participants, empathy was a key personal attribute developed through their voluntary work. Many of the volunteers were able to showcase leadership skills developed throughout their lives (both in the workplace and in their personal lives) through their various voluntary roles.

\section{Prior work/life experience:}

When talking about skills and knowledge that made them suited for their current voluntary role, work and life experiences were recurring themes. At times this was directly related to their career - for example, a person who was an accountant took on the role of treasurer for the organisation he volunteered with. For others, skills developed during their working life transferred into voluntary roles despite not being so closely related, as Participant One explained, "I used to be a teacher [...] telling people what to do, in terms of the guide bit" was one of her work experiences that made her suited for her role. Participant Twelve had decades of experience in her field which enhanced her voluntary role, "I mean I've 
worked in science all my life, ever since the 1950s". For some of the volunteers, experience in other voluntary roles led to further opportunities in other community organisations, "I got involved because of the neighbourhood watch, or neighbourhood support group" (P8).

Quick to learn/adapt to new things:

The ability to learn new things quickly and be able to adapt to new situations came through strongly in the interviews as an attribute of the volunteers that helped them to thrive in their various roles. This adaptability was recognised by the volunteers as a positive trait that made them suited for their role. For some of the volunteers, adaptability was central to their performance, as was the case with Participant Five (hospice singer), "so we need to be able to change and we need to be able to be strong enough in our singing to be able to adapt". As her role involved singing in situations that may vary greatly depending on the circumstances of individual hospice patients, there was much importance placed on the ability of herself and the other volunteers in the group to be able to change their performances at a moment's notice. It was important for the guides that they were able to quickly pick up information necessary for them to be able to help direct people around busy and often confusing locations. Often, in this role, the guides were dealing with large numbers of enquiries. In one organisation, in a three hour morning shift there could be upwards of 90 people helped: "Probably learning quickly, because you had to learn [your] way around the [organisation] very quickly [...] and learning all the other related things that you find people are asking you, yeah so you're adding to your repertoire of knowledge the whole time" (P1).

Empathy and relating to other people: 
The majority of the voluntary roles discussed involved working closely with other people, in some cases with particularly vulnerable people in many different community settings. The volunteers acknowledged that participating in this kind of close, interpersonal work further developed their own sense of empathy, and allowed them to develop their skills in terms of relating to other people in their communities:

"[I] certainly picked up a [...] fair tolerance for people's local troubles, because you know, there are a lot of troubled people around here, and there's a lot of mental health problems so, well dealing with people with mental illness, cos a lot of that comes in here" (P8).

Due to the nature of some of the volunteers' roles, some worked in close contact with people living with mental illness and their experiences of volunteering deepened their empathy for these people:

"Yes, yes, it gives you enormous empathy. Especially in the people who are struggling mentally [...] understanding that they are not silly, they're not stupid, they're [...] just battling with things that are really, you can see how they could become so big they could be battled with" (P6).

Other volunteers had lifelong experience in various forms of care work both paid and unpaid, and they were able to further develop the skills gained during that work in their current voluntary work:

"[I have] a deep underlying belief in people, and their potential, and trying to see that be developed. And I've worked a lot on that in my lifetime, so I guess those sorts of things come into play deeply in my outlook and the way that I live in the community" (P5). 
Leadership:

Although not every role entailed overt leadership, there were many examples from the volunteers that illustrated the ways in which they utilised leadership experience and further developed their leadership skills through their voluntary roles. At times, this was a clearly defined role that they undertook, such as stage managing a production:

"Oh it's amazing the number of people that think yes, I'm, you know, great as stage manager because I'm a calming influence on people and all this sort of thing. But I just look on it that what I'm doing is what I think should be done" (P2).

Other volunteers took on the additional role of training new people when they started out as volunteers. As well as this, some of the volunteers also took a leading role when they were on shift, ensuring that tasks that needed to be completed were completed, "I guess I'm just mouthy enough to just say 'Hey! Will you do that, will you do that, this still needs doing!'” (P4). Leadership was viewed by the volunteers as an important part of accomplishing the goals that they wanted to achieve through volunteering, "so I do have lots of leadership skills, that are tucked away in behind, that have worked into my family, they've worked into helping other people" (P5). Although this volunteer did not see herself as one of the current leaders in her group, she was aware of how the leadership skills that she had developed throughout her life were beneficial in her present role.

\section{Challenges and Barriers}

This research project aims to examine the relationship between positive ageing and volunteering, and an exploration of challenges and barriers to volunteering is important in that it reveals potential barriers to the benefits derived from volunteering. This section contains issues that the volunteers viewed as 
challenging either for themselves or for older volunteers in general. In the following section, some solutions suggested by the participants will be discussed.

Health and mobility:

A recurring challenge to volunteering was deteriorating health and/or mobility issues. While this was viewed by the volunteers as both a challenge and a barrier, it was also seen to be an acceptable reason not to volunteer. Health was discussed not only from a general perspective of potential challenges for older volunteers but also with reference to personal experiences of deteriorating health or changing physical abilities. Participant Five explained:

"health deterioration is a major hindrance, you know [...] I keep reasonable good health but I've had times when, you know, I've had aches and pains and just didn't feel like I could cope with much for whatever reason, but some people suffer greatly [...] so pain would be a major hindrance in people's lives, and inability to walk and move and get around, that's a huge hindrance, and that would stop a lot of people [from volunteering]".

Several volunteers also discussed particular changes that they had faced in terms of their own health that had started to impact on the way they did their voluntary work. For one volunteer, this was a decline in the amount of weight they could lift, "it's not major at the moment, it's just for me, I can't, I've got not really good shoulders and I can't bend down to lift [things]" (P4). For another, it was changes in their hearing:

"so that can be a challenge yeah, cos I'm starting to wear a hearing aid some of the time, only the trouble with hearing aids is probably a lot of people's problems, it doesn't get the small conversation [...] so hearing is something that could probably put people off [volunteering], in many situations" (P7). 
The participants took care to minimise the impact of these changes in their health and ability, but also maintained a realistic stance on how health impacted their performance in their role:

"Possibly health, realistically, because you're limited in, you can be limited by certain things. But I know that now when I walk around I don't walk as far as I used to, don't walk as fast as I used to, and I think that sort of can be quite a hindrance" (P9).

\section{Time commitments:}

The time commitment required by ongoing formal voluntary work was viewed by some volunteers as a potential barrier to participation, although most also mentioned that their own organisations were flexible in regards to changes of shift. Being committed to a regular shift was indeed a challenge personally for one of the volunteers who said:

"for me it's keeping that space free, but I don't think that would be a common one, it's knowing that [...] every Thursday you can't do anything else, that you have volunteering every Thursday [...] so people say, you know, 'what you doing Thursday?' and you say, 'oh I can't, I'm volunteering', because I'm always there on a Thursday" (P6).

For this volunteer, the requirement in such a structured environment was seen as an imposition on his freedom and ability to spend his days as he wished. Although he did not think that would be a common challenge, independently of this other participants also mentioned it as something that could put older people off volunteering: "I'm fortunate that we're fairly flexible at what I'm doing but I know some of my friends volunteer and it's gotta be, it's quite rigid it's gotta be every Wednesday or whatever" (P1). 
Transport:

A lack of access to transport options was highlighted as a potential barrier to participation in two ways. Firstly, the importance of living and volunteering on a good bus route was discussed as of central importance, especially when taking into account the use of a SuperGold Card $^{3}$ and the potential to save money in that way. The volunteers also discussed how not having access to a car or holding a current driver's licence would be a barrier to participation in the event that public transport was not an option for either getting to or carrying out the voluntary work. "I guess the other challenge is actually getting to the current location, it's not, there's no bus route there. So I mean I'm fortunate, I've got a car and still drive, so that's one of the other challenges is getting there" (P4). For one of the volunteers, her awareness of this challenge links back to her motivation for volunteering and her willingness to make use of her specific capabilities:

"I've got a car, I can afford to buy the petrol to get to wherever I need to go, which is quite good because some people don't have that and so that's a thing that I can keep in mind in doing volunteering, that if it's a job that needs a car I can be there. Whereas some people can't" (7).

Her decision-making in terms of volunteering took into account the specific gaps she could fill with her skills and the resources available to her that may not be available to other older volunteers.

\section{Finances:}

Financial security was an important theme that arose during the interviews. It

\footnotetext{
${ }^{3}$ A SuperGold Card is a discount card which can be used by NZ senior citizens and veterans. One of the most popular uses of a SuperGold Card is for free travel on public transport during offpeak hours.
} 
resonated with the participants and was approached by them in two ways. The issue of superannuation not being sufficient to survive on alone was repeated by a number of the volunteers as a potential barrier to participation in volunteering for older volunteers. A number of the participants were working either full- or part-time in addition to their voluntary roles, and one volunteer was considering whether or not volunteering was financially sustainable at present:

"I'm sort of just at the stage in my life, my life has changed a bit, and I most probably still need to earn some money for a little block of time. And so I'm thinking that instead of volunteering, I would most probably look for a job, a paying employment again. So that would, that would most probably be the one reason why I wouldn't volunteer. Cos I don't want to fill up all my days with voluntary work, when I actually might need to earn a little bit more money, yeah, and I think that you might find quite a few elderly people in that position. I would think that there's quite a lot of elderly people that would need to top up their superannuation and their income cos it's very hard to live on the superannuation, you know, these days it's not, it's not easy" (P5).

In addition to low or insecure income as a potential barrier to participation in volunteering, another issue was raised by Participant Twelve in regards to payment. When asked directly about the personal challenges of volunteering, she said, "money. I want to get paid [...] I would prefer to be paid for my work, thank you". She made it clear that the organisation she volunteered with was chronically underfunded itself, and thus did not have the money to pay the volunteers. The participant saw her voluntary role as a continuation of her career and acknowledged that the work she was doing was at a professional level in terms of quality, which illustrates the sometimes blurred lines between paid employment and voluntary work. 
Other volunteers/staff:

A recurring theme when discussing the challenges of volunteering is one that will be familiar to many. Working with others, whether they were other volunteers or paid staff within an organisation, was an acknowledged difficulty. In terms of other volunteers, many of the interviewees raised examples of volunteers who demonstrated a lack of skill in their roles:

"I had a lady a couple of weeks ago, and she was trying to let her think she knew where to go, and she took an elderly woman, I probably shouldn't say this, but she took an elderly woman with a walking stick and poor sight miles out of the way, and I thought she must have got lost and she did get lost" (P3).

Other volunteers gave examples of people who they felt were unable to show the commitment to the role necessary and missed shifts without phoning ahead or communicating their absence. Tensions were acknowledged by these volunteers as they felt the options for repercussions for this behaviour were limited by the fact that, "well, they are just volunteers" (P2), and:

"people are volunteering, so how do you - I'm not saying force them to do something, but how do you instil in them that this all leads to the place running smoothly? [...] You know you're relying on your volunteers to do that work, and how do you deal with them if they're not doing it?" (P4).

Other volunteers were not the only challenge. Some of the interviewees also discussed tensions between volunteers and paid staff. In some cases there were issues with the way organisations were being managed, for example in one organisation rules were introduced that seemed to be designed to target older volunteers, "[op shops] brought out a ruling that you weren't allowed to sit down behind the counter [...] and they lost people it almost looked as if they were trying to get rid of 
old people" (P11). Changes in policy like this were viewed as discriminatory and, in this case, were attributed to a new, younger, paid management staff member.

Another comment made in regards to the relationships between staff and volunteers called attention to the recognition granted, or lack thereof, to the efforts of volunteers:

"There seems to be a bit of a breakdown between volunteers and staff sometimes, I don't think there's always an appreciation of just how much the volunteers do [...] some volunteers don't always feel that they're appreciated [...] just occasionally you sort of think, or you say something, you know, and you're not really sure that you, that it's getting through or that it's going to be taken in to account" (P4).

In situations where volunteers worked alongside paid staff, there was an awareness that not all staff valued the contributions of the volunteers, and not all staff took the volunteers seriously.

\section{Organisational Support}

In addition to the challenges and barriers to volunteering shown above, the volunteers also shared the various ways in which the organisations they volunteered with supported them and other volunteers. Some of the following examples respond directly to earlier discussed challenges and barriers.

\section{Training:}

Most of the volunteers discussed some form of training that helped to prepare them for their role and the tasks they would be completing. This ranged from attending introductory seminars about the work and the organisation before 
starting, to attending yearly training weekends which were more in line with professional development in their roles. A common method used was for new volunteers to shadow more experienced volunteers for the first couple of weeks in the role, learning on the job. Some of the volunteers have now taken on this role with new people starting in their organisations, "like now, because I've been doing it for so long, yes if we get a new person in they will say well, [Participant Four] will teach you" (P4).

\section{Volunteer Support Staff:}

Several of the volunteers mentioned specific staff at the organisations they volunteered with as being particularly supportive. For some, this support was clearly demonstrated in the way that the staff responded to any issues brought to their attention by the volunteers:

"We have a very, very good lady who [...] runs the volunteer service. She's wonderful, she really has a wonderful capacity to understand. For instance when I had that issue with that lady a few weeks ago, this new lady, I went and talked to her [...] and she said, 'oh we'll keep an eye on her'"' (P3).

The volunteers valued being kept informed on matters relating to their roles, and credited the volunteer co-ordinators with being good communicators, "[the volunteer manager] is really good, and I'm very fond of her. She's a really very good person in her job, she also does things like, she runs the volunteers, we keep in touch with her, she's our link" (P9). Volunteers also mentioned regular meetings that they were invited to as being a good way of staying connected with the organisation's wider goals.

Support from these staff on a more personal level was also discussed in a positive light by the volunteers. Participant One appreciated the personal support shown 
to her in a time of poor health, when she received a visit from the volunteer manager and support to come back to her role only in her own time. Respect was valued in personal relationships between volunteers and staff, and the volunteers valued being appreciated and respected by paid staff at the organisations they worked with, "yeah they're quite good, all the relationships we have on a personal level you know, they're, they seem pretty accepting and they don't think [...] they don't think we're vigilantes, and things like that you know" (P8).

\section{Positive Ageing}

Positive ageing is a central theme of this thesis, and it is the main approach to population ageing taken by the New Zealand Government (Dalziel, 2001). In this section I put forth the research findings relating to positive ageing in order to build an understanding of positive ageing as defined and experienced by the research participants. This section responds to the following research question:

- What is the nature of the relationship between volunteering and positive ageing?

Some of the volunteers had not given the term much thought before participating in this project, and some viewed 'positive ageing' with healthy scepticism. Despite this, common characteristics emerged as the defining features of positive ageing, as well as a picture of the link between positive ageing and volunteering. The volunteers also discussed, in depth, aspects of ageing that they believed would make it difficult to have a positive ageing experience. These findings have been included at the end of this section under the heading 'Negative Ageing'. 


\section{Definitions}

Through discussions of personal meanings of positive ageing, a multi-faceted view of the concept emerged. These characteristics of positive ageing do include some strong similarities to the New Zealand Government's Positive Ageing Strategy, although there are points where the personal definitions and the official Positive Ageing Goals of the New Zealand Government diverge (refer to Figure 1 for the Positive Ageing Goals).

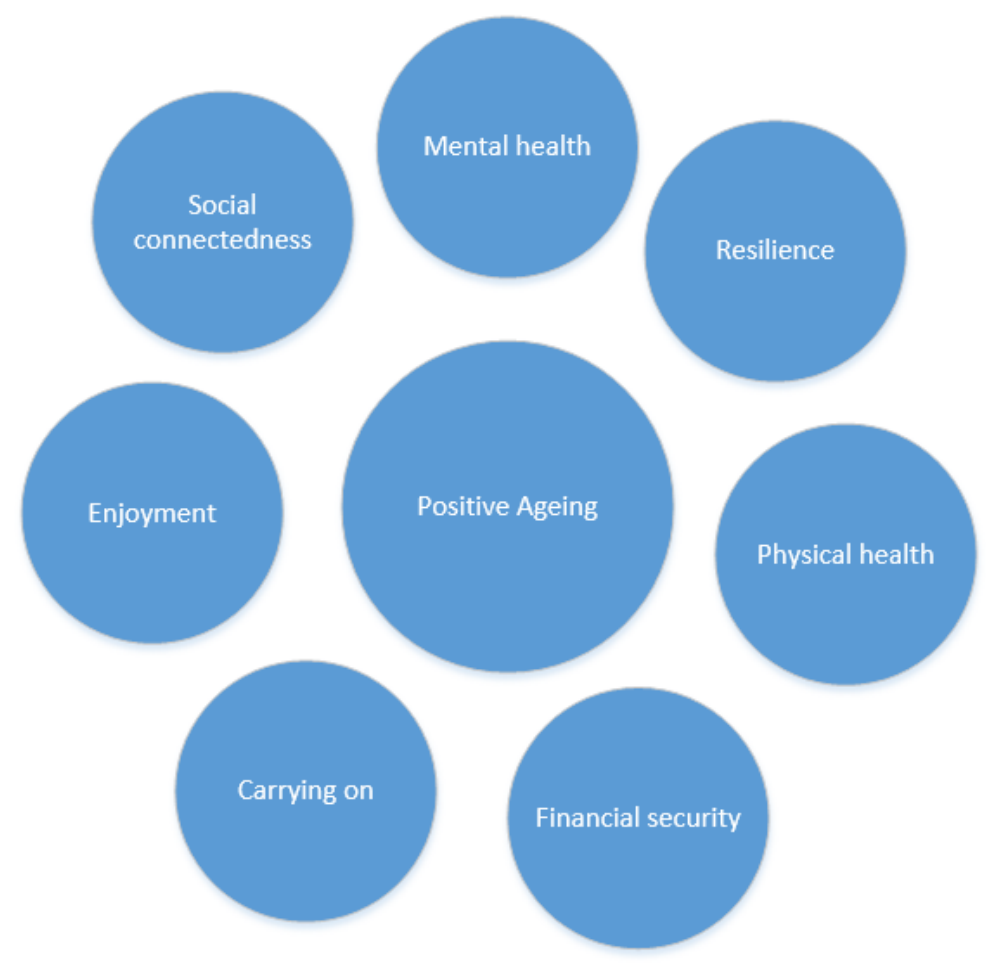

Figure 2: Participants' definitions of positive ageing.

For example, social connectedness as put forth by the participants has strong links with Goal 5, ageing in the community. Physical and mental health are addressed in Goal 2, health. However, financial security although linked with the first positive ageing goal on income does not necessarily relate to Goal 9, employment opportunities and nor does 'carrying on' translate directly to 'carrying on in employment', either. 
Health:

Maintaining good health was viewed by the participants as a key aspect of positive ageing, "health is important, look after your health, so you've got to go out and exercise and, you know, go walking" (P5). Although some participants acknowledged that they had a few health issues of their own, they largely agreed that looking after your health was something that could be managed by eating well, exercising regularly, and making sure to stay active. Personal responsibility was emphasised, "you've gotta do something for yourself about health" (P7), and numerous examples were given of the different ways in which the participants worked to maintain their health as they grew older. This included going to the gym, walking with friends and family, swimming or aqua-jogging, and exercising through voluntary work.

Another health-related theme that was prominent throughout the interviews was the importance of resilience through times of poor health, termed by Participant One as "health hiccups", which she described as inevitable but not permanently incapacitating. She and other participants discussed times in their lives when they had been temporarily unwell, but maintained a positive attitude and stayed resilient and focussed on getting better:

\footnotetext{
"There was a time, six years ago now, when I was crook, where I had to take things a lot slower and I had some cancer come on, and 6 months-worth of chemo later I was fortunately over it and just got better and continued doing it" (P2).
}

This approach highlights a view of ageing not as a period of inevitable and irreversible decline, but as a period in life where your enjoyment may be interrupted from time to time by health concerns. Attitude was recognised as of high importance in this reconceptualization of health in older age, and the 
importance of not taking a negative attitude towards every health setback was emphasised:

"In our church, we believe we all gotta carry a cross, well it's the same thing, that's part of the ageing process that the body's breaking down, and just be damn thankful you can get up every morning and walk on your own two legs and go for $i t^{\prime \prime}(\mathrm{P} 11)$.

\section{An Active Brain:}

Along with physical health, the other component of health discussed by the participants was their mental health and the health of their brains, "the brain renews itself, and instead of getting old and staticky and stuck in grooves and becoming stodgy, you actually have to put something else out there for yourself to aim towards and keep your brain active" (P5). Many of the volunteers described various activities they did with the aim of keeping their brains active, including Sudoku, listening to new music, reading widely and watching films, and attending lectures at the University of the Third Age, "you keep your mind alive, and that to me is important" (P12).

Social Networks:

The participants stressed the importance of strong social networks as a key part of a positive ageing experience. This encompassed making and staying connected with friends, spending time with family, and maintaining connections with the wider community. One way that the participants did this was through membership in clubs and groups:

"I belong to a book club, and [...] our age groups ranges from about 65 to 80 something [...] and we do stuff together, and we laugh about how we're going to cope with old age, and the rest [...] so it's a great support network, actually" (P1). 
Another participant went regularly to a lunch with a group of friends, "and we're all widowed, and we, you know, we're all in our 70s now, we started out earlier but we're all in our 70s now" (P9), and it was important to her that she had friends with similar experiences in life to her, which provided her with a social support group. The importance of ensuring that they were not only socialising with people of the same age group was also recognised as a feature of positive ageing: "So you're not stuck with one age, you're not stuck with old, you know, let's say 70 year olds or 80 year olds, that you can actually relate to the grandchildren or their grandchildren you know, or neighbour's kids" (P5). For some, maintaining social contacts of different ages and backgrounds to themselves was important in challenging them to think differently about the world, thus also working to keep their brains active. "I've listened to my granddaughter and that, and I think oh now at my age I never thought of looking at it that way, so you get a different attitude to things" (P11).

Carrying On:

Many of the participants referred to positive ageing as some variation of 'carrying on' as they always had in life, and not changing their behaviour or their activities simply because they were growing older in years: "it means not getting older [laughter], it means just to continue doing things that you've done in the past, and not really thinking about how old you are" (P2). Related to this mode of thinking is the importance of continuing independence in older age. Being able to make decisions about the way they lived and daily life was viewed as central to a positive ageing experience. Financial independence came up as particularly important in terms of leading on to other forms of independence, "that's another thing with ageing. I think financial independence is important, we're fortunate that we're in that situation" (P1). Not having to worry constantly about finances makes carrying on actively with life a viable option. Positive ageing was seen as a state 
of mind, "I think you, in fact, until your body starts to pack in, you don't get older at all. You know, my psyche is just the same as it was, as always" (P6). For some of the participants, 'carrying on' meant carrying on in work past the age when they could retire, but for others carrying on meant not withdrawing from society after reaching a certain age.

\section{Enjoyment:}

The participants maintained that an important feature of positive ageing was enjoyment and actively seeking opportunities to spend time on activities that they enjoyed: "When you're older, you know you're working on a certain time limit, you don't know what it is so you may as well enjoy it" (P11). For many of the participants there was a general attitude that they had spent much of their lives in paid employment, and now was the time to take up activities that they had not had the time for earlier in life. Volunteering was one of those activities for many participants, but they also listed art classes, social membership of a bowling club, and Japanese flower arranging among some of the activities that they spent their time doing.

\section{Volunteering and positive ageing}

As part of discussions around positive ageing, the connection between positive ageing and volunteering was explored. There were a number of connections between positive ageing and volunteering put forward by the participants, despite the aforementioned challenges and barriers to volunteering.

Social Networks: 
Volunteering provided a social outlet for the volunteers, who in most cases worked with other people as part of their role. The social aspect of volunteering was seen as particularly beneficial for people who would not normally be the type to join a club or play a sport, as the social interactions happened naturally through the voluntary work and relationships grew from there: "So this is my outlet I guess you could say, and I meet lots of people there and you know, we meet up for coffee occasionally and all that sort of thing so it provides all the things that I need, I think" (P4). For people who may have otherwise been experiencing loneliness or a disconnect from their neighbourhoods, volunteering provided them with a purpose and social connections, "well there's something to do, and being involved with people in active ongoing things [...] it's things that are actually happening". For Participant 12, volunteering in the role that she had meant that she could remain connected to her scientific community of interest, and stay in touch with research colleagues, without whom she would "curl up and die".

Healthy bodies and healthy brains:

For the majority of the volunteers, their voluntary roles involved some level of physical activity and in some cases quite a high level of activity over the course of one shift. The participants viewed this aspect of the role as clearly beneficial to their physical health, "yeah there's a lot of exercise actually, because I've sometimes worn a pedometer and in a three hour shift I do five or six kilometres, it's amazing" (P1). Although as discussed above, some of the participants had noticed that their health had been declining in recent months, rather than stop volunteering completely they modified their roles to better work for their changing physical abilities:

"Until I can't, you know, until physically I think that I can't do it anymore, and then I'll opt to do something else, you know, I'll find another something else to do. 
I mean there's still lots of things I can do [in my current role], if I just even can't lift [...] there's still things to be done" (P4).

Volunteering was viewed to be an activity that was helpful for developing and maintaining their mental abilities. Engaging in voluntary work was connected with the act of learning new things and forging new pathways in the brain: "exercise doesn't really do a lot for your mind. But learning new stuff does" (P6). For the guides in particular, the knowledge of their areas that they had to keep in mind was vast and varied, and the range of queries they fielded each shift was an important factor in remaining mentally alert, "keeping you mentally alert, that's probably another important thing with positively ageing, keeping mentally alert, so for me I'm learning things all the time, that helps that, yeah" (P1).

\section{Enjoyment:}

Central to the relationship between volunteering and positive ageing is enjoyment, "I did consider giving it up at the beginning of the year, and I said to [my husband], once I'm 80 I'm giving it up. And I thought, no, I enjoy it, just keep going [...] no I quite enjoy it, so it's still worth it" (P3). The volunteering was not being engaged in simply out of a sense of obligation or duty, and enjoyment was viewed by the participants as an important factor determining their participation in ongoing voluntary work, "good yeah, really good. As I say, I can hardly wait for the next one and we're all, all the ones I work with are the same. It's just amazing, they can hardly wait to get to the [organisation] again" (P10). One of the volunteers described a voluntary role that he left in part because aspects of the role were not enjoyable to him, and he did not see any value in continuing to spend his time doing something that he did not enjoy. 
Negative Ageing

Although this research project has a focus on positive ageing, which definitely influenced the responses given by the participants, throughout the interviews there was an awareness of aspects of life that for some people would make it a challenge to have a positive ageing experience. In this section I will put forth the views of the participants on components of 'negative ageing' ranging from health and financial insecurity to loneliness. These factors do not exist in isolation and there are overlaps between them and how they work to reinforce each other.

\section{Health:}

The participants largely positioned themselves as lucky in terms of the relatively few health issues they lived with. They were aware that they could have more significant health problems to contend with. For some of the participants, this self-positioning was a key aspect of positive ageing, "so positive ageing to me means not complaining about your physical ills and possible disabilities, just getting on with it and in fact pushing them into the background really" (P6). However, there was an understanding that not everything was easily pushed into the background, and attitude is not a solution to every health problem, "if someone's got a lot of pain [...] they're not gonna wanna go for a walk, they're not gonna wanna do some things that physically able people could do" (P7). Compassion was shown for people who were living with poor health, "I think people that have bad health, I think it's very sad for them, and I can understand how a lot of those people would feel that wasn't very positive, that their lives weren't positive or couldn't be positive" (P5). Some of the participants put poor health forward as one of the reasons people should not be expected to volunteer, while others maintained that for some people at least, "health is very important, but it doesn't necessarily stop you from doing things you know" (P9). 


\section{Financial insecurity:}

The importance of financial security and independence was discussed above in the section on positive ageing. The participants acknowledged that these were important factors, and were aware of how lacking financial security was likely to lead to a negative ageing experience, "I think people who aren't financially secure, I think old age could be pretty miserable worrying all the time, thinking about can I afford to have the heater on, and all that sort of stuff, I think life is pretty grim for some people" (P1). The participants expressed how not having enough money further reduced people's ability to experience positive ageing, "well there aren't actually friendly places you can go to really, without spending money, and you could come down here buy a cup of coffee and a bloody croissant \$10 or so, it's not cheap" (P8). Participant Eight was also describing the intersection between financial insecurity and social isolation, that options were limited for those with limited money.

\section{Social Isolation:}

Poor health and financial insecurity are both factors that the participants saw as contributing to social isolation, which was connected with a negative ageing experience. There were other contributing factors to social isolation discussed as well, such as a lack of planning and structure in life after retirement:

"Because I see a lot of people, and maybe more men, men find it very hard to adapt from their work environment that they've had, they've had a steady job all their life, then to change can be for them can be sort of soul-destroying or they feel or approach it in that way. They sort of think when they're gonna leave work they're gonna die because you know, well what are they gonna do?" (P5).

The participants said that social isolation reinforces negative thinking patterns and: 
"I can understand how easy it is for people to get small minded when they're stuck in the same place all the time, it is so easy to do. You know people that are bedridden or they can't walk, how your mind just gets smaller and smaller and it's something to be avoided" (P11).

The participants were actively avoiding that happening to them, in part through their voluntary activities, "so it [my volunteering] provides all the things that I need, I think, stop me sitting at home perhaps and not doing a lot" (P4). The emphasis was put mainly on the individual to address and avoid potential social isolation:

"I think some old people might get really lonely when they're on their own. I think loneliness is a problem, which is why the social interactions and being alert and as physically fit as you can are important and having tasks to do I think gives a structure to your week too" (P1).

\section{Representation and Stereotypes}

One of the aims of this research project is to explore the awareness that older volunteers hold of stereotypes around ageing in Aotearoa New Zealand. As discussed in Chapter Two, a range of negative stereotypes and discourses influence policymaking and public feeling around population ageing. In asking questions relating to stereotypes of ageing, I wanted to explore to what extent negative stereotypes were acknowledged by the participants and the ways that they negotiated these stereotypes. In this section I present findings in relation to stereotypes of ageing, and also the representations of ageing that emerged in the coding and analysis process. This section responds to the research question:

-To what extent do stereotypes around ageing impact on the experiences of the older volunteers? 
The changing nature of ageing

Change on a structural and an individual level was a point of reference for the participants during discussions of representations and stereotypes of old age. From a societal point of view, the participants emphasised the ways in which the experience of old age changed from the way it was experienced by their grandparents and parents, "my parents era, people aged differently, older" (P10). Reasons given for this change included the new later age for retirement, "It's different from what it is, and people are not, nowadays not as old. A 60 year old woman was quite old, 30 years ago, 40 years ago. But not now. Because they're still working, usually" (P9). In this case work created a perception of not being quite as old. Changes in the way that people dressed and presented themselves also were referenced, "but you even thought your 40s were old, I mean I thought my mother was old because you didn't have hair dye, and they dressed very old-fashionedly, so old people were old I mean it was between the age of 40 and 80 they were all old" (P11). Longer life expectancies now as compared to then also came into discussions, "in actual fact, when we were your age, people of our age actually were dying around 70, this is the, that was the life expectancy, was around 70 [...] people retired at 60 and then they were dead by the time they were $70^{\prime \prime}$ (P13).

In terms of change and ageing on an individual level, the participants openly discussed the way that their own view of older people had changed as they themselves grew older. Generally speaking their views transitioned from largely negative to more positive and understanding conceptualisations of ageing and older people, "I guess [a common stereotype would be] people thinking that you're not capable, as much as you can't do what you think you can do. When you're my age you don't look at people like that, you know" (P4). There was a recognition that as they grew older the opinions they held of older people changed and grew more accepting, due to their changing experiences of the world, "I don't see people's 
mental abilities dropping off at all which is sort of a thing I believed when I was young, that older people were thick, less agile in their heads. Maybe when I was young, they were" (P6). Opportunities were seen as continuing throughout later life rather than cutting off when they reached a certain age, "I suppose when I was younger I thought the image was of being limited in what you can do, but now I'm moving into the bracket myself I think well the sky's the limit really" (P1). This change in attitude was viewed by Participant Eleven as perhaps inevitable, and definitely understandable, "But of course as you get older, you see, as I'm sure everyone will, you see it in a different light".

\section{Negative perceptions of old age}

Despite their own, largely positive, ideas about ageing, the participants were acutely aware of the negative conceptualisations of old age perpetuated through stereotypes and representations of older people. Discussions of these conceptualisations revealed the resentment and frustration felt by the participants.

"I think the general idea of old people is that they're useless, and their mind's going [...] I really resent it [...] I'm still a person, and I might say I've done exactly the same thing in my younger years to older people and that as well, so you get what, what goes around comes around [...] but that I'm just one of a number, that I've got no personality that's worth, or any ideas that's worth anything, that's what I resent" (P11).

Common representations discussed by the participants were centred on appearance and physical ability (or lack thereof), with older people being portrayed as "hopeless. Stupid. Drooling away in a wheelchair" (P12). As opposed to themes discussed earlier in the sections on Volunteering and Positive ageing, such as adaptability and ability to learn quickly, notions of older people as "set 
in their ways" (P9) prevailed in the stereotypes the participants discussed. Representations of older people in ways that emphasised frailty and suggested extreme old age were frustrating for the participants, "what annoys me in the paper you see somebody who is 70 or something, and they say elderly 70 year old, well hello! You don't feel elderly 70, you know, that's a bit much I reckon" (P10).

The language used by the participants throughout the interviews indicated an internalisation of messages promoting a negative view of old age. The way the participants spoke about ageing and older people at times indicated a correlation between youthfulness and positivity, on the one hand, and age and negativity on the other. This came through when they spoke about friends and family. Participant Six described how he had been working to change his partner's negative feeling about age, "My lady, she's 70. But she's coming right, she is much less old than she used to be. Much less old". For Participant Six, ageing was a particularly physical phenomenon, "I think bent and stiff, and stiff in their movements yeah, physical, physical ineptitude. Yeah that's what I think old means". An anti-aging sentiment was present when discussing older people in general, "they [old people] can look very grumpy, so smiling will actually help people think well maybe you're not as old as you were or you appear, because at least you're smiling" (P7). The participants positioned themselves in a way that emphasised their youth, "I still think I'm 16 so we don't sort of think old, so nobody sort of treats us old. I don't think people do" (P13).

The fluidity of age

Throughout this research project, a prominent theme that emerged was the sense that chronological age had very little to do with whether or not a person was considered to be old. This fluidity of age was linked with the participants' shifting positionalities at different periods in their lives, and as such age was 
viewed as largely relational. As with positive ageing, attitude played an important role in determining the 'age' of a given person, "you can get 70 year olds that are sort of living like 80 year olds, and you can get 80 year olds that are still, you know, doing everything to the full" (P4). It is not the chronological age of the person that matters, but rather their attitude toward life, "so a lot depends on just how well, I think a lot depends on your attitude towards life whether you're enjoying it or want to enjoy it and that sort of stuff' (P2). Attitude is not the only factor at play here, and participants acknowledged the impact that health issues in terms of determining how old someone was, "when I worked in the rest home they were OLD, some of them were actually younger in years than me, but they were old, they were old otherwise they wouldn't have been in a rest home" (P6).

Many of the participants felt that they themselves were not 'old', and it was only when other people treated them as if they were or they caught a glimpse of themselves in the mirror that they were confronted with the way they could be viewed by outsiders, "At times when I see people and think oh they must be old, they must be in their 60s or that, and then I think [laughs] wait on, that's how old I am" (P2). The participants discussed how their thoughts on ageing had changed from when they were younger until now, "I know I've got some friends in their 80s, they don't think they're old, you know I don't know what old age is now" (P1). In experiencing ageing for themselves they learned that their identity had not changed, just their outward appearance and perhaps some of their physical abilities, "because you're really in your head, and you'll notice later on in life you don't feel old, it's just your body won't do what it used to and you look old, but you don't feel old" (P13).

\section{Conclusion}

In this chapter I have set out the findings of this research as they relate to the key research questions guiding the project. Although the chapter is divided into three 
separate sections, it is clear that there is significant overlap between experiences of volunteering, ideas about positive ageing, and representation and stereotypes. Motivations for volunteering differed among the volunteers but the reciprocal nature of the act was clearly stated, with the participants well aware of the benefits of volunteering for their own personal wellbeing, as well as that of their communities. There was a high awareness of negative stereotypes around ageing and older people, which were counteracted by the participants through their attitudes and actions. For the participants, volunteering (despite its challenges) provided an outlet to challenge stereotypes around ageing and engage in a positive ageing experience. 


\section{Chapter Five: Discussion}

\section{Introduction}

The aim of this chapter is to analyse the research findings in the context of the wider literature surveyed earlier in this thesis. The central themes of positive ageing and volunteering are explored with the chapter structured around the original research questions as set out in Chapter One. The responses to the research questions build on each other, culminating in the exploration of the central research question, what is the nature of the relationship between volunteering and positive ageing? This chapter asserts a place for this thesis within the literature, as the older volunteers who participated in this project have asserted places for themselves within their communities.

In carrying out this research project, I have utilised a qualitative research design which has supported my social-constructivist epistemological stance. Throughout the project I have engaged with older volunteers in Wellington through semi-structured interviews, and in presenting the research findings I have brought the voices of the participants to the forefront of my analysis. Privileging the voices of the participants enabled me to present a rich, descriptive view of their life-worlds, putting their experiences and insights at the centre of the analysis.

This research presents findings from a small group of older volunteers, and I acknowledge that they cannot stand for all volunteers: their stories and insights are theirs alone. The research participants also acknowledged their relative privilege in terms of their positions as formal volunteers. Access to transport, their financial situations and support systems put them in a position where they were able to give their time as volunteers, and they recognised that this would not be possible for many people who do not have access to the same opportunities or resources. 
RQ1: What is motivating older people in Wellington to volunteer in their communities?

Reciprocity has been identified as a factor underlying many motivations for older people's participation in voluntary work (Narushima, 2005; Barlow \& Hainsworth, 2001). The research findings illustrate a range of motivations for volunteering given by the participants that reflect this reciprocal nature of volunteering. The motivations ranged from those related to entities outside of themselves to those closely linked with their own personal well-being. In terms of external motivations for volunteering, some of the participants were engaged in voluntary work for reasons linked to their families and upbringings, their commitment to their communities and identification of needs within the community that they could meet (Rawsthorne, 2012), and even their commitment to New Zealand. Personal motivations for volunteering included the enjoyment that the participants gained from their work, the improvements that volunteering brought to their physical and mental health, and the way volunteering provided a way for them to stay connected to others in their community.

It has been argued that pressure is imposed on older people to contribute to society in light of neoliberal economic policy shifts that emphasise individual responsibility and economic productivity, as discussed by Stephens et al. (2015). This pressure can be seen as part of the complexity involved in rejecting the discourse of 'ageing as societal burden'. The stated motivations of the participants show that the ways in which participants constructed their identities clearly contrasted this discourse. The participants positioned themselves as the helpers and not the helpless, whilst not shying away from discussing times in their lives when they had been vulnerable and dependant on others. By acknowledging that they had times when they relied on others for help, they were also often able to help those in need, the participants go beyond simple 
ideas of individual responsibility and explore the give and take of intertwined community relationships.

Gibson-Graham (2007) argue for an expanded view of productivity in their work on community economies. This expanded view is useful in forming an understanding of the many ways that older people are motivated to contribute to their communities through voluntary work. Some of the participants stated that they were motivated in part by a desire to share their skills and knowledge with others in the community. By using unpaid labour as the mechanism through which to utilise their abilities, older volunteers disrupt mainstream understandings of economic exchange (Gibson-Graham, 2007). The contributions made by the participants and, in turn, the benefits they gain through this participation are part of a complex web of relationships that extends beyond the reach of a purely economic-based understanding of productivity. Within a community economies approach there is room to advocate for an understanding of productivity that takes into account more than simply monetary value.

RQ2: What skills and knowledge are older volunteers bringing to and gaining through their voluntary work?

The PAS asserts that older people have "skills, knowledge and experience to contribute to society" (Dalziel, 2001, p. 9), and Rawsthorne (2012) indicates that for older volunteers, there is a connection between prior work and life experience, and the transferral of skills into a voluntary role. The findings of this research demonstrate the wide range of skills and knowledge utilised and accumulated through the participants' voluntary work. They range from the professional to the personal and help to enhance understandings of the value of volunteering (Gibson-Graham, 2007). The research findings challenge stereotypes of older people as unwilling or unable to learn, and are an example 
of the many ways that the participants address the positive ageing Goal 10: "increasing opportunities for personal growth and community participation" (Dalziel, 2001, p. 23).

The relationship between paid work and volunteering was emphasised by the participants. They described a range of professional experience that they saw as contributing to their suitability for their roles as volunteers (Warburton \& McDonald, 2009), although the roles did not necessarily link directly with past work experience, and their skills from work were transferrable into a variety of positions. The importance of structure in retirement was highlighted, and the continuation of their working lives through formal voluntary roles was one method used by the participants to cope with this often daunting lifestyle change. Though they were still free on most days of the week, formal volunteering, with its structured shifts, provided a means for the participants to continue to grow and develop their skills.

The research findings relating to leadership skills gained or further developed through voluntary roles support Rawsthorne's (2012) research on informal community leadership. By and large the participants were not engaged in overt leadership roles, but informally took on leadership responsibilities throughout their time as volunteers. This led to greater support for the operations of the organisations that they were working within. Some of the participants exhibited a reluctance to proclaim themselves as leaders despite acknowledging the aspects of their practice that involved leadership, a phenomenon also described in Rawsthorne's (2012) study. This unwillingness to emphasise their skills in leadership illustrates the pragmatic nature of many of the participants as well as the general reticence associated with 'kiwi culture' on the whole.

Wiles and Jayasinha (2013) discuss care for place as a means of making sense of older people's contributions to their communities, and state that volunteering is just one of many ways that older people contribute. Empathy, defined by Davis 
(as cited in Pedwell, 2011) as "imaginatively experiencing the feelings, thoughts and situations of another" (p. 165), was identified as a key personal attribute that the participants had developed through their voluntary work in the community. Care and empathy are interconnected because through the act of caring, empathy can be developed. In turn, increased empathy may work to increase expressions of care. Care has been discussed as a key motivator for older people involved in volunteering (Wiles \& Jayasinha, 2013; Rawsthorne, 2012; Hardhill \& Baines, 2009) and the findings of this study show that the act of volunteering has also deepened the participants' capacity for care. Interacting with a wide range of community members through their roles as volunteers led the participants to be better able to understand and express care for their communities not only whilst volunteering, but in other aspects of their lives as well including their relationships with friends and family members (Wiles \& Jayasinha, 2013).

RQ3: What challenges and barriers to participation in volunteering do the older volunteers identify, and what solutions do they put forward to address these?

The inclusion of discussions of challenges and barriers to older people's participation in volunteering in this research works towards presenting a more nuanced view of volunteering and positive ageing, and away from a romanticised portrayal of voluntary work (Skinner et al., 2013). Wiles and Jayasinha (2013) acknowledge the tendency to utilise either overly positive or overly negative stereotypes when discussing ageing and older people. Including a solutions-focussed section on challenges and barriers in the semi-structured interviews was my attempt to find some middle ground. The findings illustrate the participants' empathy through their thoughtful contributions to this research question, in response to which they spoke about challenges that they had personally faced as well as imagined challenges or barriers that other older 
people may face in relation to volunteering. Challenges and barriers were identified in relation to health limitations, time constraints, the accessibility of transport, financial (in)security, and interpersonal relations. Although some of the participants were hesitant to share these more negative views at first, the participants were all aware of challenges and barriers associated with volunteering either experienced personally or potentially by others.

Transport emerged as a potential barrier to participation in voluntary work for some older people. Concerns around transport related both to private cars and public transport systems. The costs associated with maintaining a private car could be a barrier to people with limited financial means (Tang, Morrow-Howell, \& Choi, 2010). Furthermore, the inaccessibility of some volunteering locations not on main bus routes could mean that older people without driver's licenses or access to their own cars could be reliant on other people to transport them. Some people feel uncomfortable about relying on others for their transportation as it reinforces the feeling of being a burden, and also this kind of help is not available to everyone. An alternative to cars is the use of public transport systems, which have also been identified as a potential barrier to participation in volunteering.

The SuperGold Card offers free travel on public transport for cardholders during off peak times in Wellington. This was viewed in a largely positive light by the participants, though some participants raised concerns about possible changes that the New Zealand Government may make to the SuperGold system further limiting access. They saw this to be concerning because free public transport provides an opportunity for older people living on limited incomes in Wellington to remain active and connected to their communities, through volunteering or other activities. A 2015 review of the public transport aspects of the system has indeed revealed changes that will be introduced in June 2016 which will restrict access to the free public transport to those who have a transport smartcard, which they will need to purchase themselves (Ministry of Transport, 2015). This change 
has been framed as insignificant by the Ministry of Transport, who state that the costs involved with purchasing a smartcard will be small in comparison with the benefits gained through the access to public transport. However, any changes that threaten to restrict vulnerable people's access to public goods must be viewed with caution. The people who will be impacted the most by changes such as these are also the people who need the access to free public transport the most.

The vulnerable position of older people with limited financial means has been discussed in the literature in terms of how neoliberal economic policies and discourses around ageing that emphasise activity and contribution will negatively impact on their abilities to experience positive ageing (Asquith, 2009; Stephens, et al., 2015; Lie et al., 2009). Financial insecurity was recognised by the participants to be a barrier to participation in volunteering, and could lead to the further disengagement of such people from society. Asquith (2009) is clear that "sociality is not cost-neutral" (p. 265) and participation in voluntary work nearly always involves monetary costs to the volunteer, either in terms of costs they incur through their roles, or income they miss out on. For some older people this may mean they are unable to participate in voluntary work due to a need to remain in or return to paid employment to meet their living costs, a situation described by one of the participants.

Health limitations were identified as a key challenge in the findings, and health is also a central concern in the literature on population ageing, one that contributes to the discourse of 'ageing as societal burden'. Onyx and Benton (1995) discuss how ageing is viewed by many in the West to be a process of inevitable decline, and explore the implications of this view on policy approaches addressing population ageing. The research findings reject a simplified view of age as decline, and through their descriptions of their own and others' experiences the participants highlighted another way of viewing the relationship between ageing and health. It was accepted that health issues could be a barrier 
to volunteering for some people, but many of the participants described how they themselves overcame these barriers and continued in voluntary work. Health was conceptualised by the participants in terms of 'health hiccups' rather than following a linear path of continual deterioration. Due to this conceptualisation, health limitations were described as events that could be temporarily disruptive to everyday life, rather than as indicative of moving into a new stage of life.

Central to achieving the vision of the PAS is its aim to change the attitudes of all New Zealanders towards ageing. This finding supports a change in attitudes towards the way that we think about health and ageing. Some approaches to ageing and volunteering treat health setbacks as enormous obstacles to older people's effectiveness in voluntary work. These attitudes must be challenged in order to further contest discourses treating ageing as a societal burden. Organisations can work to challenge attitudes around health and ageing by demonstrating flexibility and understanding when a volunteer is experiencing a period of ill-health. In the case of people experiencing long-term health issues or disability who wish to participate in their communities through voluntary work, organisations can provide support through the provision of roles which can be modified to make the most of their abilities, as also suggested by Kam (1996) and Lie et al. (2009).

The research findings illustrate the central role that organisations with a base of volunteers can play in addressing some of the identified challenges and barriers to participation in voluntary work. In terms of formal voluntary roles, the importance of having a well-organised, supportive and capable volunteer coordinator was emphasised by many of the participants, supporting Narushima's (2005) research findings. As well as this, Warburton and McDonald (2009) state the importance of volunteer managers recognising "capacity and interest" ( $p$. 836) in potential volunteers, no matter their age, as opposed to engaging in ageist practices of volunteer recruitment. Such a person is well-placed to address 
concerns and issues raised by volunteers, provided they do not harbour ageist prejudice. The participants emphasised a need for flexibility in relation to their changing life circumstances as one of the key supports that organisations could offer their volunteers. Where possible, it was recognised that small financial contributions, for example to the costs of transport for the volunteers, were appreciated and helpful (Tang et al., 2010). However, it was generally understood by the participants that the organisations they volunteered with did not always have the funding to provide this support. In order to mitigate the challenges and barriers associated with volunteering and ageing, an awareness and willingness among volunteer organisations to be flexible in relation to the needs of their diverse body of volunteers is necessary.

RQ4: To what extent do stereotypes around ageing impact on the experiences of the older volunteers?

Stereotypes, discourses and identity have played a significant throughout this research project. As discussed above, the findings show that the participants were well aware of dominant discourses framing older people as unproductive burdens on society. The findings also illustrate the awareness among the older volunteers around negative stereotypes around ageing which they viewed to a certain extent as outdated and irrelevant. Through the process of co-constructing their identities as volunteers, assisted by the focus of this project and volunteering (being their reason for participating in it), the participants were able to position themselves in opposition to ageist stereotypes presenting older people sitting around doing nothing, being drains on society. Through exercising their agency in deciding to become or remain volunteers in the face of changing circumstances, the participants actively challenge condescending views such as those of Hazan (1994, p. 44), of volunteering as something granted to older people as a tokenistic way of contributing. In support of the work of Wiles and Jayasinha 
(2013), this decision made by many to continue with volunteering by altering their tasks to suit their abilities challenges both an overly positive view of 'successful' ageing as being ageing without challenges, and negative views of older people as burdens and solely the receivers of care.

The findings illustrate the frustration felt by the participants in response to experiences of other people reading them as 'old' based on their outward appearance, with all the reductionism associated with the use of that term (Hazan, 1994). The participants who expressed these feelings were critical of people who declined to take into account their life experiences and knowledge, instead reducing them to a single category of existence. Volunteering is am method utilised by the participants to negotiate this frustration. By emphasising their continued participation and contribution to society both in their daily lives and through partaking in this research project, the participants were asserting their identity in opposition to the negative stereotypes of ageing. As discussed above, key to the vision of the PAS is its aim to change everyone's attitudes towards ageing (Dalziel, 2001). This research shows that the participants were engaged in this work of changing attitudes, and they openly advocated the notion that they were role models for others, both to educate the general public about potential roles of older people and to show other older people what they could achieve, with opportunities they may not be aware of.

What is the nature of the relationship between volunteering and positive ageing?

The research findings illustrate the complex and entangled relationship between volunteering and positive ageing, and support a nuanced and balanced approach to understanding both (Wiles \& Jayasinha, 2013). The findings identified various intersections where the two met, ranging from maintaining and improving 
mental and physical health, strengthening and broadening social networks, to the enjoyment of daily life. Throughout the research, the participants emphasised the importance of choice and agency as instrumental in their positive experiences as volunteers, supporting the conclusions of Stephens et al. (2015) around the importance of policy approaches supporting older people to contribute to their communities in the ways that they choose. Volunteering should not be expected of all older people, and I agree with Skinner et al. (2013) that it should not be romanticised, but at the same time it should be made clear that it is one of many options which contribute to positive ageing experiences, not the only option.

Positive ageing as articulated internationally and in the Aotearoa New Zealand context comes in many different forms. A key distinction can be made between holistic approaches such as that advocated by WHO (2002) in their active ageing policy framework, and economic approaches as adopted by the OECD (Taylor, 2011). Within Aotearoa New Zealand, the PAS falls somewhere in between the holistic and the economic approach. Economic overtones to the vision and the goals of the PAS carry over into the Wellington City Council's (2012) PAP, which emphasises the importance of "supporting and engaging with [older] people as they move into retirement", as it is "crucial for the city's economic future" (p. 1). The understanding of positive ageing advanced in this research project aligns more closely with a holistic approach to ageing, and as has been discussed above rejects traditional understandings of productivity and ageing in favour of an expanded view which takes into account physical and mental well-being, social connections and reciprocity and care. This research adds personal perspectives to the positive ageing literature, building on and adding qualitative depth to the more impersonal policy approaches utilised by the New Zealand Government and Wellington City Council.

This research has sought to extend understandings of positive ageing through the exploration of personally held definitions of positive ageing that were 
expressed by the participants. In doing so, this research has contributed to an expanded discursive space on ageing. As discussed above, the participants were open with regards to the positive and negative aspects of ageing and volunteering, and realistic rather than idealistic with regards to their positive ageing experiences. The diversity in their experiences and definitions challenges reductionist views of ageing that position all older people into one homogenous group with the same needs (Hardhill \& Baines, 2009).

In particular, one research finding illustrates this expanded space well: the perspectives on health put forth by the participants. When considered together, health and volunteering provide a lens through which to understand the concept of ageing. Health has been discussed above in relation to challenges and barriers to participation in volunteering, and it also recurred in the findings on definitions of positive ageing. Physical and mental health were central elements to the definitions of positive ageing held by the participants, and volunteering was seen by many of the participants to contribute to their ongoing health and wellbeing. Health situations were not idealised, but nor were health challenges seen as insurmountable problems. Health limitations did not necessarily totally restrict their participation in the activities that they chose to spend their time engaged in. The organisations they volunteered with supported a variety of changing needs, in ways that bring to mind Lie et al.'s (2009) recommendations for Age Concern Newcastle to include "more flexible volunteer roles incorporating small amounts of volunteering that would suit people with an illness or disability" (p. 714). The organisations and volunteers worked together to challenge reductionist views of volunteering, unsettling the strict connotations of 'formal' voluntary work and revealing the interconnected nature of formal and informal volunteering.

Volunteers are acknowledged by UN Volunteers (UNV) to play a significant role in achieving the SDGs (UNV, 2015). Ageing is viewed globally as both a success of, and a challenge to, 'development' and by positioning volunteering within the 
wider population ageing discourse, it is possible to build an understanding of the roles of older volunteers as forces of their own and others' development. The findings show that volunteering was understood by the participants to be beneficial to themselves and to others in their communities, either through enjoyment, increased activity, or improved empathy and the ability to understand other people's life situations. These findings work towards addressing the ambivalence around ageing as a success and a challenge, by presenting a less binary view.

Running through the multiple understandings of volunteering and positive ageing put forth in this thesis is the importance of attitude. The participants were aware that they had limited control over their changing life circumstances but emphasised the impact that attitude can have in determining a response to those changes, whether they are negative or positive. The impact of a positive attitude towards challenges are an important aspect of building resilience which can help enhance experiences of both positive ageing and volunteering (Wiles \& Jayasinha, 2013; Gattuso, 2003). Taking a positive and open minded attitude towards challenges and changes in circumstances let to the continued participation in voluntary work for most of the participants, with a recognition that 'everyone has their cross to bear'. Volunteering was perceived by many of the participants as something so enjoyable that they overcame other challenges in order to continue in their roles.

Closely related to attitude is the wider theme of enjoyment. Volunteering was recognised by the participants in the research to be a highly enjoyable and positive activity to engage in (Lie et al., 2009). Enjoyment is one of the central links between volunteering and positive ageing to emerge through this research project. The findings show that volunteering is seen as an enjoyable activity for those that participated in the research, but it needs to be made clear that by no means does that mean volunteering will be enjoyed by everyone. Volunteering 
is one of many ways that older people choose to participate in society (Stephens et al., 2015), and should not be thought of as the sole pathway to positive ageing. The participants acknowledged that formal volunteering was not for everyone, but also made it clear that through their actions they were hoping to act as role models for people who were not aware that volunteering was something they could participate in, and that there were people who might enjoy volunteering as much as they did but were not informed about the many different options available to them. Narushima (2005) advocates for the expansion of traditional understandings of productivity to extend to the broader sphere of "social and moral economy" (p. 582), within which enjoyment surely has a place.

\section{Conclusion}

In this chapter I have worked to answer the research questions that have guided this project. In doing so I have located the research findings within the wider literature surrounding volunteering and positive ageing. I began by exploring the motivations for volunteering given by the participants in relation to external pressures to position themselves as productive members of society. I then discussed the range of skills and knowledge both professional and personal that the participants bring to and develop through their participation in voluntary roles. Challenges and barriers to participation in volunteering were discussed in terms of the importance of considering them in order to present a nuanced view of volunteering. I then discussed the significance of age-based stereotypes and emphasised the role of volunteering as a means utilised by the participants to challenge and resist them. Finally, the relationship between volunteering and positive ageing was considered in relation to wider discourses of population ageing, with a view towards using volunteering and positive ageing as a way of extending understandings of productivity and contributions to people and place. 


\section{Chapter Six: Conclusions}

In this thesis I have sought to develop an understanding of the relationship between volunteering and positive ageing in Wellington. This final chapter of the thesis will first summarise the research and set out the key conclusions of this project as they respond to the primary research aim. I then discuss recommendations for future practice and areas for further research. To conclude the chapter, I finish with some final reflections on the research.

\section{Overview of thesis}

Following Chapter One, which set out the research aim and central research questions, the literature review in Chapter Two served to locate the thesis within the context of international perspectives on population ageing and development, which position ageing as both a success of and potential challenge for 'development', with older people viewed as a burden on society. The chapter went on to examine the ways in which active ageing policies globally and locally have worked to reduce anxieties around population ageing by reframing ageing in a positive light. This reframing often has economic undertones relating to the economic productivity of older people and the contributions they make to society. At times, this positive reframing goes too far into the realm of unrealistic pressures and expectations on older people to continually contribute. Chapter Two then examined the literature on older volunteers through the lenses of reciprocity, care and empowerment in order to examine the motivations for volunteering given by older people, and to contrast these individual reasons with those promoted by the government.

In Chapter Three I expanded on aspects of my positionality and social constructivist epistemology that have shaped the qualitative approach to this project. Semi-structured interviews were a key methodological approach in this 
research and they were crafted through an iterative process of learning that further developed with each new interview. A logical framework for thematic analysis was developed based on the overarching research questions, and this framework assisted in the communication of my understandings and interpretations of the data.

Chapter Four utilised this framework and set out the research findings guided by the key research questions that they related to. The chapter was divided into three sections: volunteering, positive ageing, and representations and stereotypes. Although the sections were distinct, ideas around each concept overlapped and intertwined. It was found that although there were some commonalities between the participants' definitions of positive ageing and definitions put forth in the PAS, there were also key areas of divergence. Overall and despite its challenges, the participants found volunteering to be a positive outlet for challenging stereotypes and engaging in experiences of positive ageing.

In Chapter Five I discussed the research findings and situated them within the wider literature and theoretical environment. This discussion worked to address each of the research questions in turn before culminating in a response to the overarching question guiding this project, what is the nature of the relationship between volunteering and positive ageing? It was found that volunteering and the participants' own definitions of positive ageing have the potential to extend understandings of productivity and the ways that older volunteers contribute to people and place.

\section{Key conclusions}

The reciprocal nature of volunteering was emphasised during this research project through an exploration of the participants' motivations and experiences (Barlow \& Hainsworth, 2001; Narushima, 2005). This exploration of volunteering 
revealed multi-faceted relationships with exchanges of benefits between the older volunteers, the organisations they worked within, and the people and communities they worked to help inherent in its practice. This exchange of benefits flows in multiple directions, and it was found that the participants gained as well as gave of themselves. Many participants linked the social, mental and physical health benefits that they received though their voluntary work directly with their positioning of volunteering as part of a positive ageing experience.

This research has found that empathy and care are intertwined and central to voluntary work undertaken by the participants. Caring for place indicates a sense of ownership and belonging which is demonstrated through this research finding. The roles that the participants volunteered in varied greatly but regardless of role, through their interactions with other the participants were able to develop their empathy and understanding of people and their needs in their communities and social circles. This finding illustrates the capacity for continued personal development of the older volunteers and shows the way that they use their voluntary roles to further position themselves as active, caring members of their communities.

The way that the participants conceptualised health was found to differ from mainstream understandings of ageing as a process of inevitable decline. This view of ageing as decline feeds into the discourse of ageing as societal burden. In contrast to this view, the participants conceptualised health in terms of health hiccups - poor health was viewed as an occasional disruption to normal life rather than as signalling the beginning of a process of decline. This learning adds to understandings of the ways that individuals conceptualise health which can impact both the way that they receive treatment and care during periods of poor health and the type of support offered to them during periods of long- or shortterm illness. 
The research findings illustrate the need to expand understandings of productivity and economies when considering the relationship between volunteering and positive ageing. Economic approaches to population ageing as a development issue frame older people in terms of their ability or lack thereof to contribute to the economy. A simplistic market-based view of economic exchange cannot capture the complexity inherent in the relationships between volunteers and their communities. Through an expanded understanding of productivity that takes into account social and moral elements as well as the purely economic, we are better able to appreciate the value of the contributions that older volunteers and older people in general make to their communities and to society (Narushima, 2005).

The roles of the organisations in which the older people were volunteering were found to be of great importance. The organisations were found - for the most part - to be supportive and flexible in the face of the changing life circumstances of their volunteers. In cases where organisations were shown to be unsupportive or too restrictive, participants and people they knew chose not to volunteer with them any longer. If organisations wish to maintain a strong and dedicated volunteer base, robust management and organisational capabilities are required. In maintaining this support, organisations can continue to play a role in the positive ageing experiences of older people who choose to volunteer.

The resistance of stereotypes and negative representations of older people by the participants in this research illustrates the frustrations felt in facing ageist prejudice. Volunteering was one of the methods employed by the participants in order to reject negative stereotypes presenting older people as burdens on society, and became a way for the participants to emphasise their roles as active older people. The personal definitions of positive ageing held by the participants were not overly idealised and it was accepted that not although all aspects of life will be 'positive', negative experiences do not necessarily entail 'negative ageing'. 
Positive ageing was not conceptualised as an external imperative, in terms of success and failure and responsibilities to wider society, but as a matter of individual attitudes and circumstances.

\section{Recommendations for practice}

Based on the above research conclusions, certain recommendations for future practice can be made. These relate to potential volunteers, organisations, and the New Zealand Government and Wellington City Council.

Over the course of this research project from the early stages of planning and recruitment through to the interviews with participants, I have been made aware of the vast array of volunteer opportunities in Wellington for people with a range of interests and abilities. The participants in the project were aware of people who would perhaps personally benefit from volunteering but who were not aware of the range of possibilities. I recommend wider promotion of volunteering in various forms in order to reach larger numbers of potential volunteers. This promotion could be carried out in a number of ways, for example:

- Advocacy from current volunteers, sharing about their experiences with friends, family and others

- Advertising from organisations in a variety of places and spaces. This does not necessarily need to be an expensive endeavour: I've learnt through this research about the reach of a well-placed poster on a community noticeboard

- Media promotion through interviews and feature stories, not limited to National Volunteer Week (one week in June each year in New Zealand) but spread out through the year 
Important in all of these approaches is the need to present a realistic view of volunteering which captures the rewarding aspects without concealing potential challenges.

Organisations that rely on volunteers to achieve some or all of their aims need to be aware of challenges and barriers that can limit participation in voluntary work, and be responsive to those that they are able to address. Where possible, I recommend the provision of a small amount of funding to meet travel costs incurred by volunteers (Tang et al., 2010). It is also important that volunteer organisations recognise their volunteers for the contributions that they make, including all of the 'extra' work that they do outside of their ordinary roles. Organisations should be mindful of their role in creating a supportive and enjoyable environment.

The New Zealand Government and the Wellington City Council in adopting the PAS and the PAP have made a commitment to supporting positive ageing practices in Aotearoa New Zealand. The economic undertones to these approaches are cause for concern. Learnings from this research project have led to the following recommendations for the New Zealand Government and the Wellington City Council. I recommend that both the Government and the Wellington City Council, along with the Greater Wellington Regional Council ${ }^{4}$, are mindful of the impacts that changes to the current SuperGold Card public transport scheme will have on vulnerable older people. Transport links are instrumental in assisting many older people to remain active and engaged in their communities, and incurring extra costs in order to maintain access to free public transport may serve to exclude those who need access the most. A joint approach to these upcoming changes is needed in order to ensure vulnerable older people do not miss out on their entitlements. I also recommend that the

\footnotetext{
${ }^{4}$ The Greater Wellington Regional Council is responsible for Wellington's public transport system, Metlink.
} 
New Zealand Government seriously considers the impact that changes to the retirement age will have on the voluntary sector. If large numbers of people delay retirement due to concerns of the government about the labour force or personal financial situations, the impacts on the voluntary sector could be severe in terms of reduced capacity.

\section{Areas for future research}

An area for future research that needs further exploration in the New Zealand context is volunteering for those with limited mobility or disabilities. Due to time constraints in the present project I was unable to explore this in any depth but I suggest that research could be undertaken exploring the opportunities that are available for older people with limited mobility/disabilities that wish to participate in voluntary work, as well as learning about the experiences of those already partaking in such work.

Another area for exploration is the blurred space between formal and informal volunteering. Throughout the interviews with participants it became clear that although they may have had 'only' one or two formal voluntary roles, they were engaged in large amounts of extra work and support to their organisations which was not always recognised. These activities do not quite fit the definition of informal volunteering as 'lots of little kindnesses' put forth by Warburton and McLaughlin (2005), but also do not fall within the normal role descriptions of their formal volunteering. It would be interesting to explore this further to work towards a more complete understanding of the contributions of volunteers to society. 


\section{Final reflections}

As Cornwall (2007) has said, "words make worlds" (p. 471), and I add that 'attitudes shape experiences', to a certain extent. This research has explored the complexities of the relationship between volunteering and positive ageing. Through the lens of volunteering the research has explored the role of stereotypes and discourses in global and local responses to population ageing as a development issue, and the power of older people to resist them. In this new era of the SDGs wherein development is framed in terms of individual as well as global action, I would like to conclude by reflecting on the personal impacts this research project has had on me.

I have studied, worked, lived, and socialised with people from a variety of backgrounds including a range of age groups. However, it was not until I was in the midst of this research project that I began to truly realise the significance of intergenerational connections, and the role they play in changing attitudes around ageing. Learning about how constructions of ageing as a societal burden and as a process of decline/withdrawal from society impact on policy responses to population ageing, and then speaking with people about how these representations impact them personally has made me more aware of how individual attitudes and behaviours can contribute to such responses. A heightened awareness of ageism as it subtly and not-so-subtly infiltrates mainstream culture has encouraged me to be careful with the language that I use and the images of older people that I perpetuate. This study's focus on the diverse experiences and views of older volunteers has allowed me to contribute to the growing body of work recognising and honouring their contributions to their communities and has introduced me and the people in my life to one of many ways in which older people resist ageism and stereotypes. 


\section{References}

Asquith, N. (2009). Positive ageing, neoliberalism and Australian sociology. Journal of Sociology, 45(3), 255-269.

Barbour, R. (2008). Introducing qualitative research: a student guide to the craft of doing qualitative research. London: Sage Publications Ltd.

Barlow, J., \& Hainsworth, J. (2001). Volunteerism among older people with arthritis. Ageing and Society, 21, 203-217.

Biggs, S. (2001). Toward critical narrativity: stories of aging in contemporary social policy. Journal of Aging Studies, 15, 303-316.

Boudiny, K. (2013). 'Active ageing': from empty rhetoric to effective policy tool. Ageing and Society, 33, 1077-1098.

Bowling, A. (2008). Enhancing later life: how older people perceive active ageing? Ageing \& Mental Health, 12(3), 293-301.

Castree, N., Kitchin, R., \& Rogers, A. (2013). A dictionary of human geography. Oxford: Oxford University Press.

Chacko, E. (2004). Positionality and praxis: fieldwork experiences in rural India. Singapore Journal of Tropical Geography, 2(1), 51-63.

Clarke, A., \& Warren, L. (2007). Hopes, fears and expectations about the future: what do older people's stories tell us about active ageing? Ageing E Society, 27(4), 465-488

Conway, D. (2014). Neoliberalism: globalization's neoconservative enforcer of austerity. In Desai, V. \& Potter, R. (Eds.), The companion to development studies (3 ${ }^{\text {rd }}$ Ed.) (pp. 106-111). New York: Routledge.

Cornwall, A. (2007). Buzzwords and fuzzwords: deconstructing development discourse. Development in practice, 17(4-5), 471-484.

Creswell, J. W. (2014). Research Design (4th ed.). London: SAGE

Publications Ltd.

Dalziel, L. (2001). The New Zealand positive ageing strategy: towards a society for all ages - He anga oranga kau mō ngā whakatipuranga 
katoa. Wellington: Ministry of Social Policy.

Davey, J., \& Glasgow, K. (2006). Positive ageing: a critical analysis. Policy Quarterly, 2(4), 21-27.

Elwood, S. A., \& Martin, D. G. (2000). "Placing” interviews: location and scales of power in qualitative research. The Professional Geographer52(4), 649-657.

Escobar, A. (1995). Encountering development: the making and unmaking of the third world. Princeton, NJ: Princeton University Press.

Esteva, G., \& Prakash, M. S. (1996). From global thinking to local thinking. In Rahnema, M., \& Bawtree, V. (Eds.), The post-development reader (pp. 277-289). New Jersey: Zed Books.

Foster, L., \& Walker, A. (2013). Gender and active ageing in Europe. European Journal of Ageing, 10, 3-10.

Gattuso, S. (2003). Becoming a wise old woman: resilience and wellness in later life. Health Sociology Review, 12(2), 171-177.

Gibson-Graham, J.K. (2007). Surplus possibilities: post-development and community economies. In Ziai, A. (Ed.) Exploring post-development: theory and practice, problems and perspectives (pp. 145-162). New York: Routledge.

Gibson, C., \& Woolcock, M. (2008). Empowerment, deliberative development, and local-level politics in Indonesia: participatory projects as a source of countervailing power. Studies in Comparative International Development, 43(2), 151-180.

Hardhill, I., \& Baines, S. (2009). Active citizenship in later life: older volunteers in a deprived community in England. The Professional Geographer, 61(1), 36-45.

Hazan, H. (1994). Old age: constructions and deconstructions. Cambridge: Cambridge University Press.

HelpAge International. (2014). Older people in ageing societies: burden or resource? Chiang Mai: Author.

Howard, J., \& Wheeler, J. (2015). What community development and citizen 
participation should contribute to the new global framework for sustainable development. Community Development Journal, 50(4), 552-570.

Jaffe, D. J., \& Miller, E. M. (1994). Problematizing meaning. In Gubrium, J. F., \& Sankar, A. (Eds.), Qualitative methods in ageing research (pp. 51- 64). London: SAGE Publications Ltd.

Jones, P. S. (2000). Why is it alright to do development 'over there' but not 'here'? Changing vocabularies and common strategies of inclusion across the 'first' and 'third' worlds. Area 32(2), 237-241.

Kam. P. K. (1996). Empowering elderly people: a community work approach. Community Development Journal, 31(3), 230-240.

Lassen, A. J., \& Moreira, T. (2014). Unmaking old age: political and cognitive formats of active ageing. Journal of Aging Studies, 30, 33-46.

Leontowitsch, M. (2012). Researching later life and ageing: expanding qualitative research horizons. Hampshire, UK: Palgrave Macmillan.

Lie, M., Baines, S., \& Wheelock, J. (2009). Citizenship, volunteering and active ageing. Social Policy \& Administration, 43(7), 702-718.

Long, G. (2015). The idea of universality in the sustainable development goals. Ethics \& International Affairs, 29(2), 203-222.

Luborsky, M. (1994). The identification and analysis of themes and patterns. In Gubrium, J. F., \& Sankar, A. (Eds.), Qualitative methods in ageing research (pp. 189-210). London: SAGE Publications Ltd.

Mason, J. (2002). Qualitative researching (2nd Ed.). London: SAGE Publications Ltd.

Matthews, S. (2008). The role of the privileged in responding to poverty: perspectives emerging from the post-development debate. Third World Quarterly, 29(6), 1035-1049.

McGregor, A. (2009). New Possibilities? Shifts in post-development theory and practice. Geography Compass, 3(5), 1688-1702.

Merriam, S., Johnson-Bailey, J., Lee, M., Kee, Y., Ntseane, G., \& Muhamed, M. (2001). Power and positionality: negotiating insider/outsider 
status within and across cultures. International Journal of Lifelong Education, 20(5), 405-416.

Mendes, F. R. (2013). Active ageing: a right or a duty? Health Sociology Review, 22(2), 174-185.

Ministry of Transport. (2015). Sustainable funding of the SuperGold Card transport concession scheme. Wellington: Author.

Narushima, M. (2005). ‘Payback time’: Community volunteering among older adults as a transformative mechanism. Ageing and Society, 25(4), 567-584.

Nustad, K. (2007). Development: the devil we know? In Ziai, A. (Ed.) Exploring Post-development: theory and practice, problems and perspectives (pp. 35-46). New York: Routledge.

Office for the Community and Voluntary Sector, New Zealand (2007).

Mahi Aroha: Maori perspectives on volunteering and cultural obligations. Wellington, New Zealand: Author.

Office for Senior Citizens. (2008). Positive ageing goals and objectives - as at May 2008. Retrieved from https://www.msd.govt.nz/about-msd-and-ourwork/publications-resources/planning-strategy/positive-ageing/goalsand-objectives-may-2008.html

Office for Senior Citizens. (2015). Report on the positive ageing strategy. Retrieved from https://www.msd.govt.nz/documents/what-we-cando/seniorcitizens/positive-ageing/msd-17470-2014-ageing-strategyreport-final.pdf

Onyx, J., \& Benton, P. (1995). Empowerment and ageing: toward honoured places for crones and sages. In Craig, G. \& Mayo, M. (Eds.), Community empowerment: a reader in participation and development (46-58). London: Zed Books.

Palmore, E. B. (1999). Ageism: negative and positive. New York: Springer Publishing Company.

Pedwell, C. (2011). Affective (self-) transformations: empathy, neoliberalism and international development. Feminist Theory, 13(2), 163-179. 
Pieterse, J. (2001). Development theory: deconstructions/reconstructions.

London: SAGE Publications Ltd.

Potter, R. (2014). Measuring development: from GDP to the HDI and wider approaches. In Desai, V. \& Potter, R. (Eds.), The companion to development studies ( ${ }^{\text {rd }}$ Ed. ) (pp. 56-59). New York: Routledge.

Prime Ministerial Task Force on Positive Ageing. (1997). Facing the future: a possible way forward. Wellington: Department of the Prime Minister and Cabinet.

Ranzijn, R. (2010). Active ageing - another way to oppress marginalized and disadvantaged elders?: Aboriginal elders as a case study. Journal of Health Psychology, 15(5), 716-723.

Rawsthorne, M. (2012). Older people building better communities through informal community leadership. Canberra, Australia: National Seniors Productive Ageing Centre.

Rubin, H. J., \& Rubin, I. S. (1995). Qualitative interviewing: the art of hearing data. London: SAGE Publications Ltd.

Skinner, M. W., Joseph, A. E., \& Herron, R. V. (2013). Spaces of resistance or acquiescence? Learning from media discourses on the role of voluntarism in ageing communities. Environment and Planning A, 45(2), 438-450.

Statistics New Zealand. (2015). 2013 Census QuickStats about people aged 65 and over. Retrieved from http://www.stats.govt.nz/Census/2013census/profile-and-summary-reports/quickstats-65-plus/populationoverview.aspx

Stephens, C., Breheny, M., \& Mansvelt, J. (2015). Volunteering as reciprocity: Beneficial and harmful effects of social policies to encourage contribution in older age. Journal of Aging Studies, 33, 22-27.

Stewart-Withers, R., Banks, G., McGregor, A., \& Meo-Sewabu, L. (2014).

Qualitative Research. In Scheyvens, R. (Ed.), Development fieldwork (2nd Ed.) (pp. 59-80). London: SAGE Publications Ltd.

Tamasese, T., Parsons, T., Sullivan, G., \& Waldegrave, C. (2010). Cultural 
obligations and volunteering. Wellington: Family Centre Social Policy Research Unit.

Tang, F., Morrow-Howell, N., \& Choi, E. (2010). Why do older volunteers stop volunteering? Ageing and Society 30(5), 859-878.

Taylor, R. (2011). Ageing, health and innovation: policy reforms to facilitate health and active ageing in OECD countries. Paper presented the OECD Conference on Health Reform: Meeting the challenge of ageing and multiple morbidities, Paris, France. Retrieved from: http://www.oecdilibrary.org/social-issues-migration-health/health-reform/ageing-healthand-innovation_9789264122314-5-en

United Nations Population Fund \& HelpAge International. (2012). Ageing in the twenty-first century: a celebration and a challenge. New York: Authors.

United Nations. (2011). Current status of the social situation, wellbeing, participation in development and rights of older persons worldwide. New York: Author.

United Nations. (2002). Political declaration and Madrid international plan of action on ageing. New York: Author.

United Nations. (2015a). Sustainable development goals. Retrieved from https://sustainabledevelopment.un.org/sdgs.

United Nations. (2013). World population ageing 2013. New York:

Author.

United Nations. (2015b). World population ageing 2015. New York: Author.

UN Volunteers. (2015). Sustainable development goals: information and guidance for volunteer organizations. Retrieved from http://www.unv.org/fileadmin/docdb/pdf/2015/Resources/UNV_Q_A_o n_SDG_2015_web.pdf

Vincent, J. A. (1999). Politics, power and old age. Buckingham: Open University Press.

Vos, R., Ocampo, J., \& Cortez, A. (Eds.). (2008). Ageing and development. London: Zed Books Ltd.

Walker, A. (2015). Active ageing: realising its potential. Australian Journal on Ageing, 34(1), 2-8.

Walker, A. (2002). A strategy for active ageing. International Social Security 
Review, 55(1), 121-139.

Warburton, J., \& McDonald, C. (2009). The challenges of the new institutional environment: an Australian case study of older volunteers in the contemporary non-profit sector. Ageing and Society, 29(05), 823-840.

Warburton, J., \& McLaughlin, D. (2005). 'Lots of little kindnesses': valuing the role of older Australians as informal volunteers in the community. Ageing \& Society, 25, 715-730.

Wellington City Council. (2012). Positive ageing policy. Wellington: Author.

World Health Organization. (2002). Active ageing: a policy framework. Geneva: Author.

World Health Organization. (2012). Good health adds life to years. Geneva: Author.

World Health Organization. (2000). Social development and ageing: Crisis or opportunity? Geneva: Author.

World Health Organization. (1999). Ageing: exploding the myths. Geneva: Author.

Wiles, J. L., \& Jayasinha, R. (2013). Care for place: the contributions older people make to their communities. Journal of Aging Studies, 27, 93101.

Ziai, A. (2007). Exploring post-development: theory and practice, problems and perspectives. New York: Routledge.

Zimmermann, H., \& Grebe, H. (2014). “Senior coolness": living well as an attitude in later life. Journal of Aging Studies, 28, 22-34. 


\section{Appendix One: Victoria University of Wellington}

\section{Ethics Forms}

Appendix 1a: Ethics Approval Form

TE WHARE WÁNANGa O TE OPOKO O TE IKA A MÃUI

MEMORANDUM

Phone $\quad 0-4-4635480$

Email susan.corbett@vuw.ac.nz

\begin{tabular}{l|l}
\hline TO & Alice Clowes \\
\hline COPY TO & John Overton \\
\hline FROM & AProf Susan Corbett, Convener, Human Ethics Committee \\
\hline
\end{tabular}

\begin{tabular}{l|l}
\hline DATE & 28 April 2015 \\
\hline PAGES & 1 \\
\hline
\end{tabular}

\section{\begin{tabular}{l|l}
\hline SUBJECT & Ethics Approval: 21887
\end{tabular}}

Absolutely Positively Ageing: Exploring Older Volunteers'

Experiences of Community Development in Wellington

Thank you for your application for ethical approval, which has now been considered by the Standing Committee of the Human Ethics Committee.

Your application has been approved from the above date and this approval continues until 4 March 2016. If your data collection is not completed by this date you should apply to the Human Ethics Committee for an extension to this approval.

Best wishes with the research.

Susan Corbett

Human Ethics Committee 


\section{Appendix 1b: Participant Information Sheet}

\section{Participant Information Sheet}

Research Project Title: Absolutely Positively Ageing: Exploring Older Volunteers' Experiences of Community Development in Wellington

Researcher: Alice Clowes, School of Geography, Environment and Earth Sciences, Victoria University of Wellington

This study fulfils a partial requirement for the completion of my Masters of Development Studies. The purpose of this research is to explore the lived experiences of older people who are active as volunteers in the Wellington region, and to discover the ways in which volunteering can contribute to a positive ageing experience.

This research project has received approval from the Victoria University Human Ethics Committee.

I am inviting anyone aged 65 years or older who is a volunteer in the Wellington region to participate in this study. Participants will be asked to take part in an interview lasting (approx.) one hour. Permission will be asked to record the interview, and if you choose not to be recorded I will take notes instead. A summary of the interview will be sent to you to be checked.

Participation is voluntary, and you will not be identified personally in any written report produced and/or published in academic journals as a result of this research. All material collected will be kept confidential, and will be viewed only by myself and my supervisor Prof. John Overton. The thesis will be submitted for marking to the School of Geography, Environment and Earth Sciences and deposited in the University Library. It is intended that one or more articles will be submitted for publication in scholarly journals, and a summary of the findings may be sent to local community organisations, the Wellington City Council and the Office for Senior Citizens.

Should any participant feel the need to withdraw from the project, they may do so without question at any time before $28 / 08 / 2015$, and the data collected up to that point will be destroyed. Participants can withdraw by contacting me using the contact details below. Data collected during the study will be securely stored electronically in a password protected file, and destroyed five years after the end of the project.

If you have any further questions or would like to receive further information about the project, please contact me at +64278455257 or alice.clowes@vuw.ac.nz, or my supervisor Prof. John Overton, at + 6444635281 or john.overton@vuw.ac.nz.

\section{Alice Clowes}




\section{Appendix 1c: Participant Consent Form}

\section{Participant Consent Form}

Research Project Title: Absolutely Positively Ageing: Exploring Older Volunteers' Experiences of Community Development in Wellington

Researcher: Alice Clowes, School of Geography, Environment and Earth Sciences, Victoria University of Wellington, New Zealand.

- I have been given and have understood an explanation of this research project. I have had an opportunity to ask questions and have them answered to my satisfaction.

- I understand that I may withdraw myself (or any information I have provided) from this research project by emailing alice.clowes@vuw.ac.nz before 28/08/2015 without having to give reasons.

- I understand that any information I provide will be kept confidential to the researcher and their supervisor.

- I understand the published results will not use my name, and that no opinions will be attributed to me in any way that will identify me.

- I understand that the tape recording of interviews will be wiped at the end of the project unless I indicate that I would like them to be returned to me.

- I understand that the data I provide will not be used for any other purpose or released to others without written permission.

Please indicate by ticking the boxes below which of the following apply:

$\square$ I would like to receive a summary of this interview once it has been transcribed.

$\square$ I would like to receive a summary of the results of this research when it is completed.

I agree to this interview being audio recorded.

\begin{tabular}{|l|l|}
\hline Signed: & Signed: \\
Name of Participant: & Name of Researcher: \\
Date: & Date: \\
\hline
\end{tabular}




\section{Appendix Two: Semi-structured interview protocol}

NB: This protocol was used to guide the interviews, so not every question was asked in each interview and there were questions that were asked not captured here.

1. Volunteering - background information

- $\quad$ 1. 1 Who do you volunteer with? And how long have you been volunteering with them?

- 1. 2 What would an average shift look like for you? Probe: tasks, responsibilities, hours per week/month

- 1. 3 Is volunteering something you've always done? Or is it something you've picked up more recently?

- 1. 4 What motivated you to become a volunteer?

2. Volunteering - skills/knowledge

- 2. 1 When you decided to volunteer with [org], what was it about yourself that made you suited for the role?

- 2. 2 Can you tell me about the skills that you've gained through your time as a volunteer?

3. Volunteering and positive ageing

- 3.1 Can you tell me about what positive ageing means to you?

- 3. 2 How does volunteering fit into 'positive ageing' for you?

\section{Volunteering - challenges/barriers}

- 4. 1 What would you say are the main challenges of volunteering that you're aware of for older volunteers?

- 4. 2 Is there anything that would put you off volunteering, or that would make it harder for you to be a volunteer?

- 4. 3 Thinking about some of those issues, what kind of supports does [org] have in place to help address them?

\section{Stereotypes about ageing}

- 5. 1 How do you think older people are portrayed in the media?

- 5. 2 Has anyone ever treated you like an "old person"?

\section{Wrapping up}

- 6.1 Is there anything else you would like to add about what we've talked about today? 